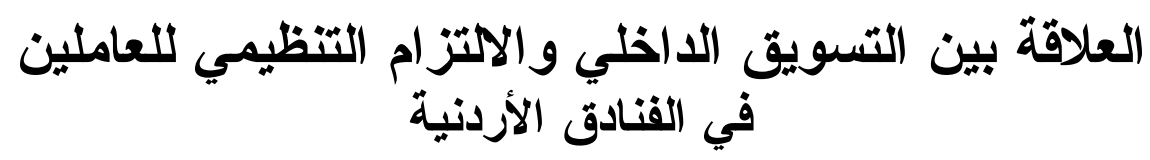

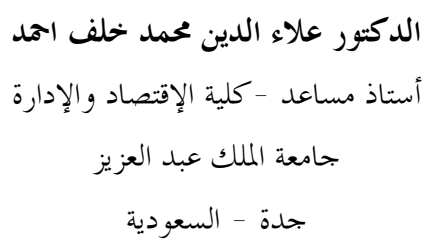

Aladdin.a.n@hotmail.com

$$
\text { أدكتور أسعد محاد موسى أبو رمان }
$$

assdham200@hotmail.com

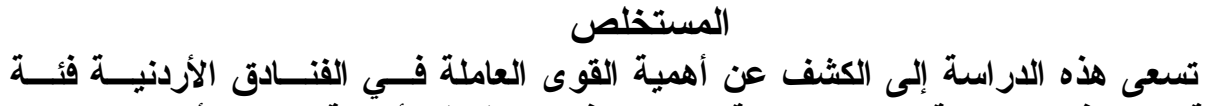

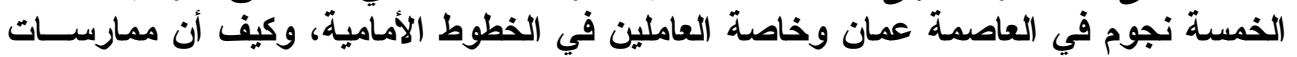

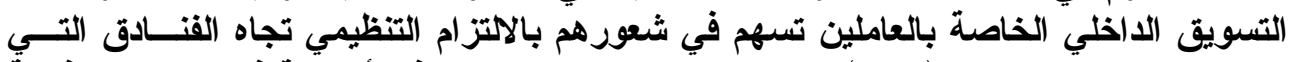

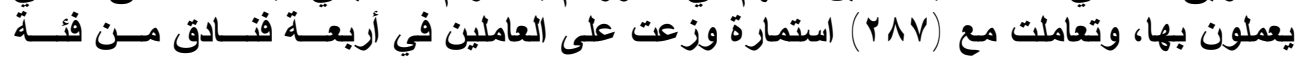

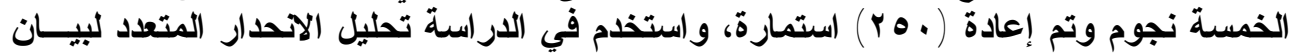

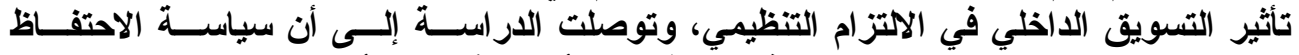

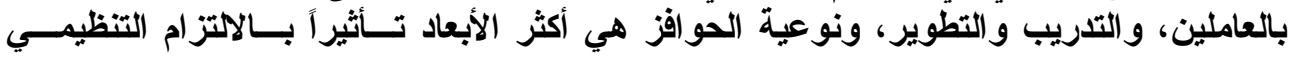

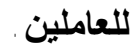
الكلمات المفتاحية: التسويق الداخلي، الالتزام التظيمي، الفنادق، العاملين، الأردن.

\title{
The Relation between Internal Marketing and Organizational Commitment for Workers in Jordanian Hotels
}

\author{
Asad H. Abu Rummana (PhD) \\ Associate Professor \\ Department of Marketing \\ University of Applied Sciences \\ Jordan
}

AlaaAldin M. Ahmed (PhD)

Assistant Professor

College of Economics and Administration

King Abdul Aziz University

Saudi Arabia

\begin{abstract}
The aim of this study is to explore the importance of employees in Jordanian five star hotels in Amman in particular the front stage employees and to what extent the internal


marketing practices related to employees may participate in the sense of organizational commitment towards their hotels. Data collection involved research questionnaire technique was employed to recruit 287 employees representing four five stars hotels in Amman. This study used the multiple regression analysis to show the impact of internal marketing practices on the organizational commitment. The study findings showed that employee' retention policy, training and development, and incentive methods considered as the most influential factors on the employees organizational commitment. This paper contributes to previous research by adding to existing knowledge regarding what constitutes internal marketing. The study makes key recommendations towards employees' retention, training and development and incentives.

\section{Key Words:}

Internal marketing, organizational commitment, hotels, employees, Jordan.

\section{المقدمة}

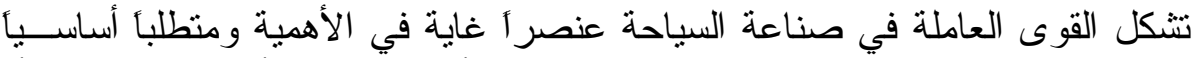

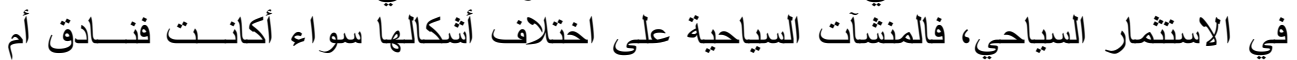

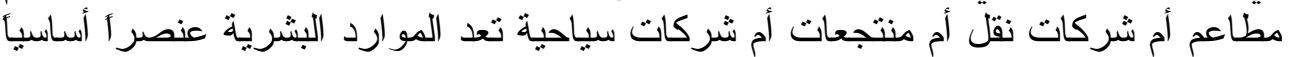

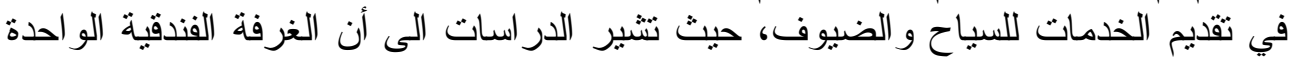

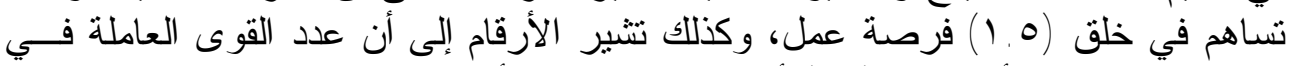

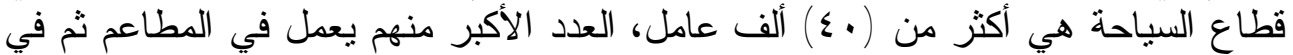

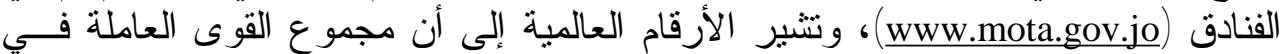

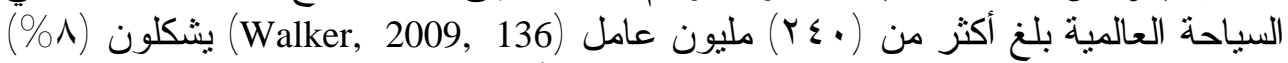

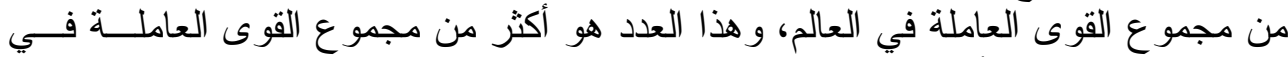

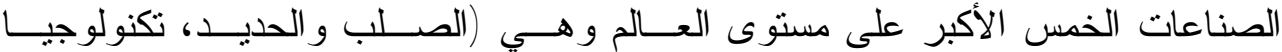

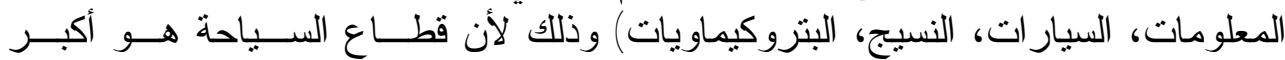

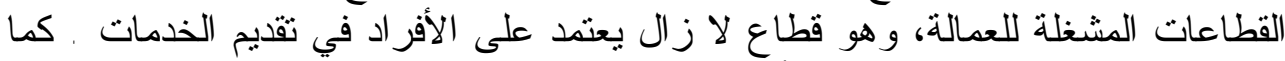

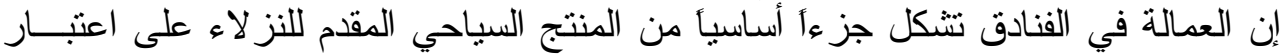

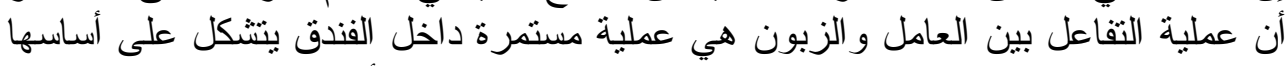

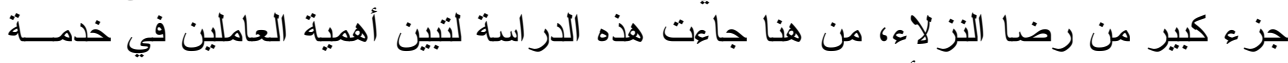

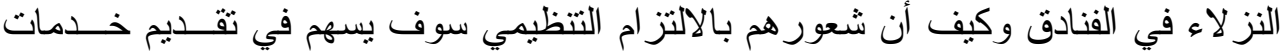

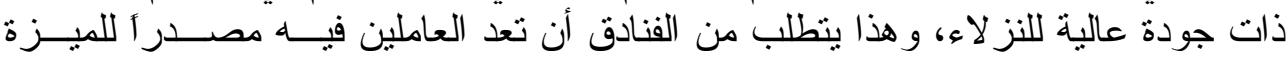
التنافسية وبالتالي تحقيق الأهداف المرجوة لأهو

$$
\begin{aligned}
& \text { منهجية الار اسةة } \\
& \text { مشكثة الار اسة الأة }
\end{aligned}
$$

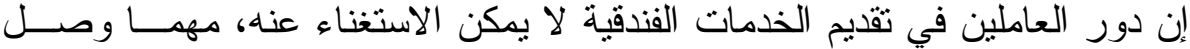

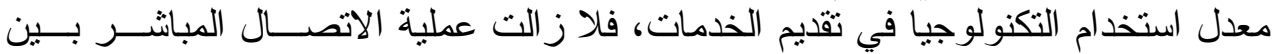

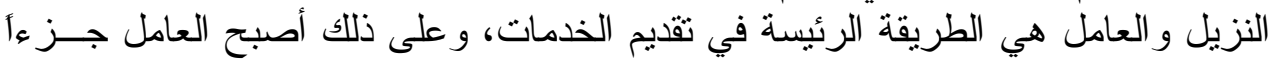

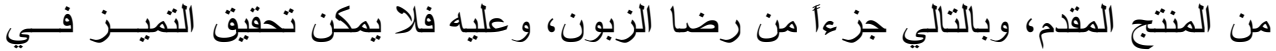

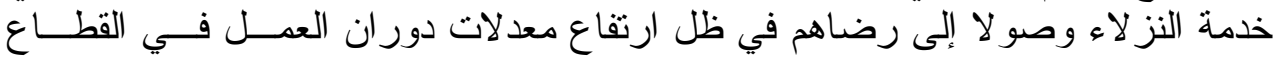


أبو رمان وأمدان

الفندقي في الأردن و التي تصل إلى ( (\%) ما يجعل عملية الاحتفاظ بالعـاملين أمسرا

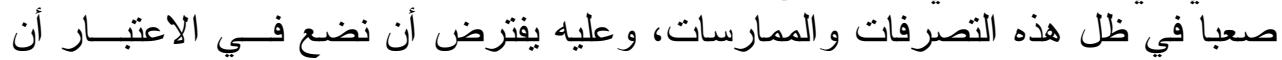

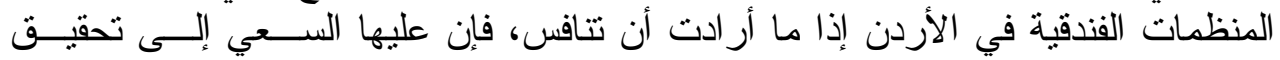

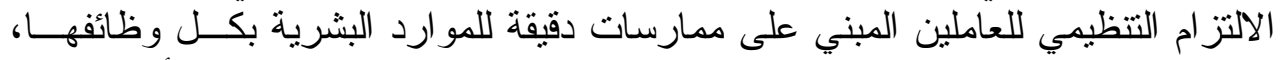
و اعتبار العامل هو مصدر التميز وتحقيق الميزة التتافسية في سوق الضئية الضيافة الأردني.

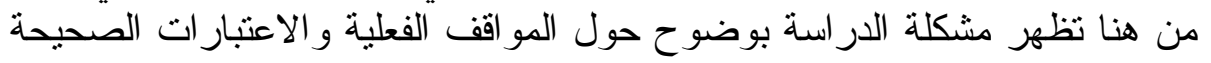

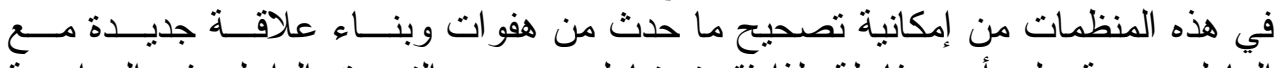

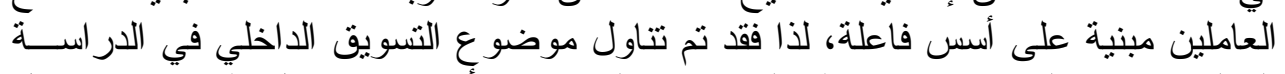

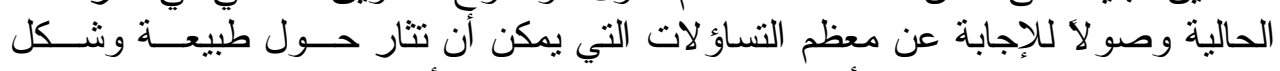

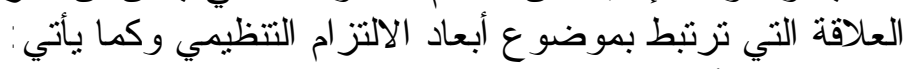

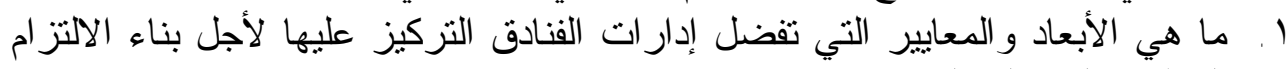

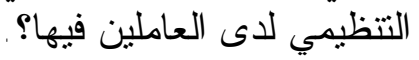

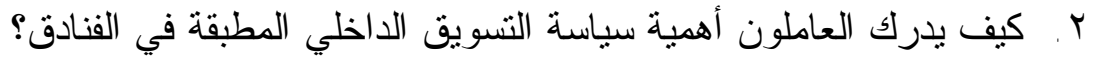

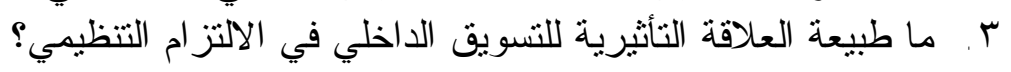

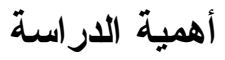

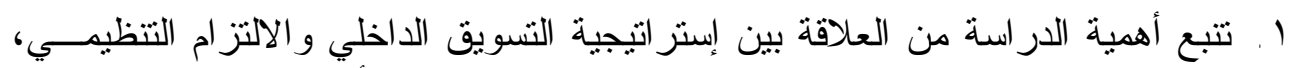

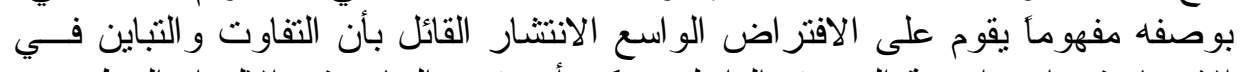

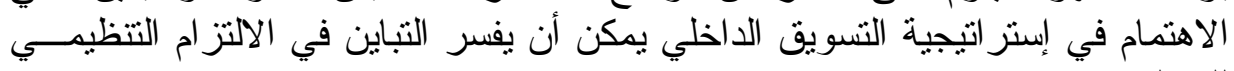

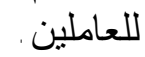

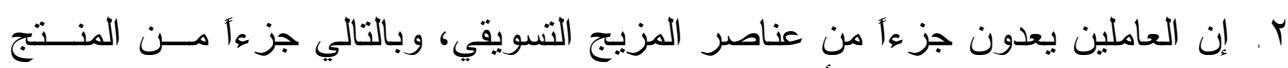

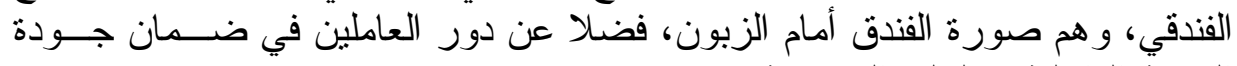

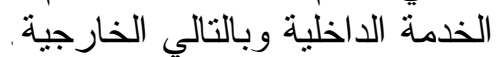

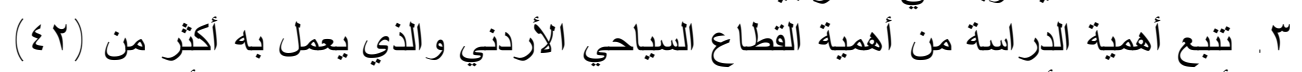

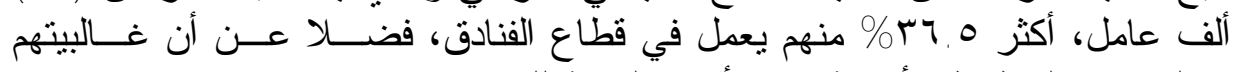
يعملون في الخطوط الأمامية من الأقسام التابعة للفندق.

\section{هاف الدراسة}

1. الكثف عن تقييمات العاملين في الفنادق الأردنية لأبعاد إستر اتيجية التسويق الداخلي،

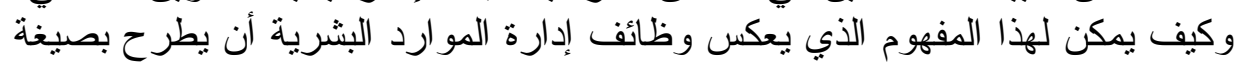

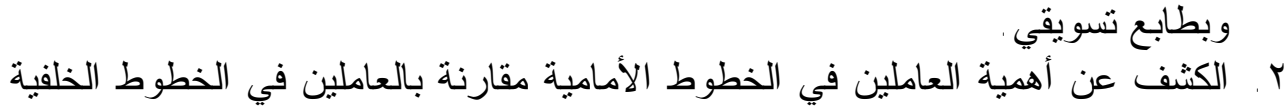

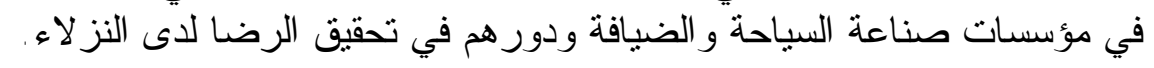

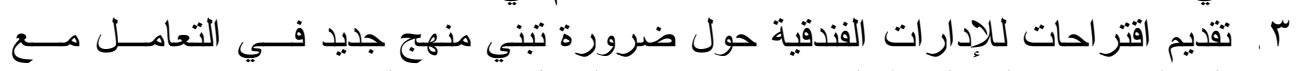

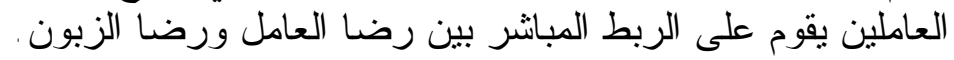

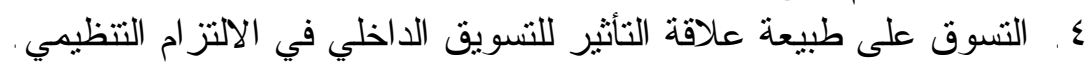


الفرضية الرئيسة: Ho " ليس هناك علاقة تأثيرية بين إستر اتيجية التسويق الــــاخلي

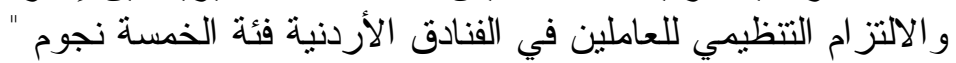

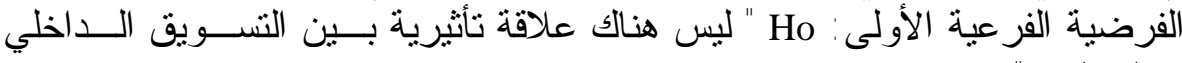
و الالنز ام العاطفي " العبد الفرضية الفر عية الثنانية: Ho " لبس هناك علاقة تأثيرية بــين التســويق الـــاخلي

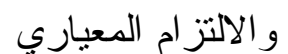
الفرضية الفرعية الثالثة: Ho " ليس هنالك علاقة تأثثرية بـين التســويق الـــاخلي

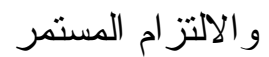

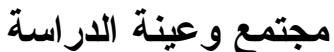

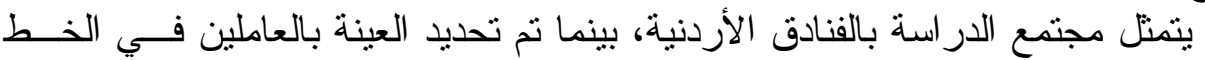

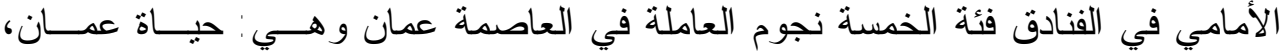

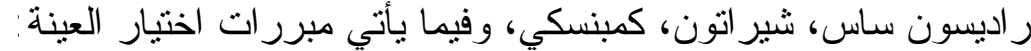

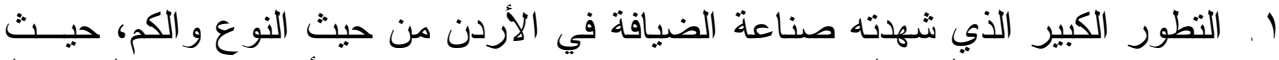
وصل عددها إلى (乏NV) فندقأ من مختلف الدرجات يعمل فيها أكثــر مسن (14000)

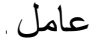
r r سيتم اختيار هذه العينة من الفنادق فئة الخمسة نجوم و التي تصنف بأنها الأكبر مسن فئس

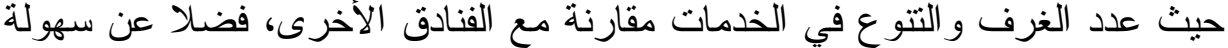

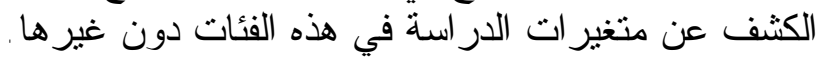

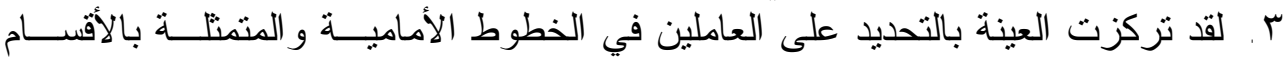

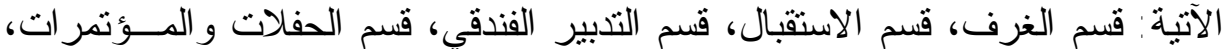

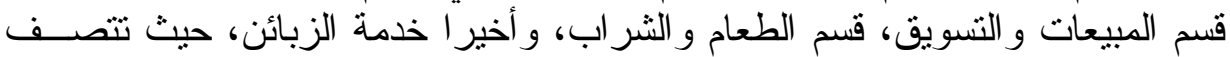

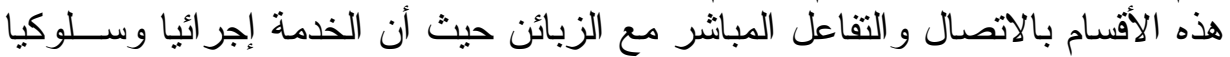

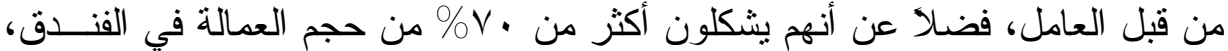

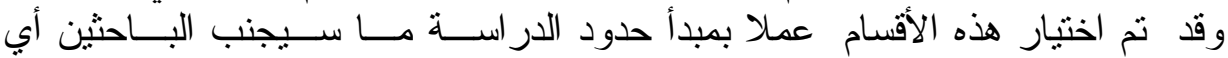
تكاليف، فضلا عن الحدود الزمانية المتعلقة بمدة إجر اء الدراسة الألة

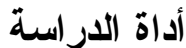
تمثلت أداة الدراسة بالاستمارة وكانت من النوع المركب المكثوف الهذف، احتوت

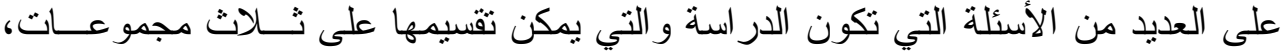
وفيما يأتي توضيح لهذه المجمو عات من الأسئلة:

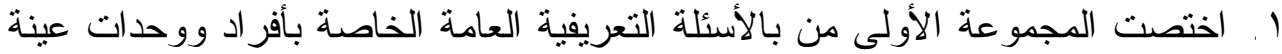

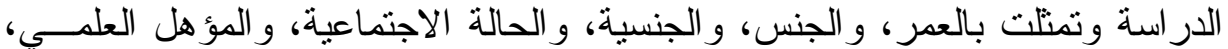

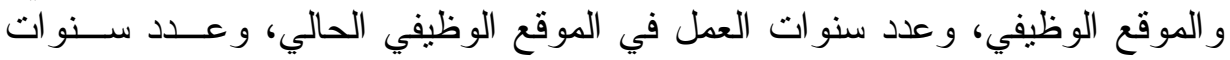
العمل في الفندق، فضلا عن اسم الفندق. 


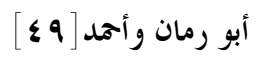

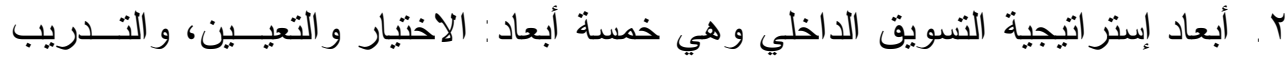

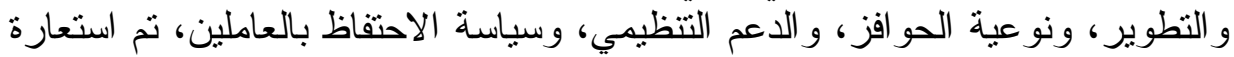

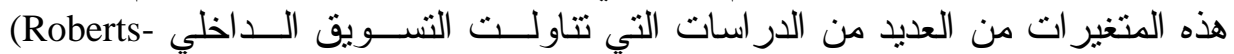
Lombard, 2010 ; Greene, et al., 1994 ; Turkoz and Akyol, 2008 ; Ahmed, et al., 2003 ; Hwang and Chi, 2005 ; Rydberg and Lyttinen, 2005 ; Rafiq and (Ahmed, 1993 ; Snell and White, 2009 ; Farzad, et al., 2008)

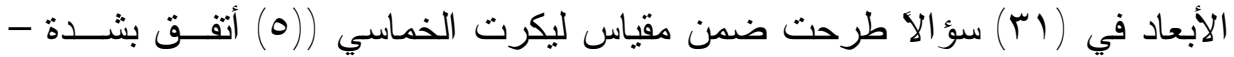

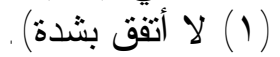

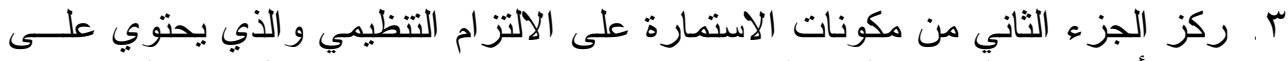

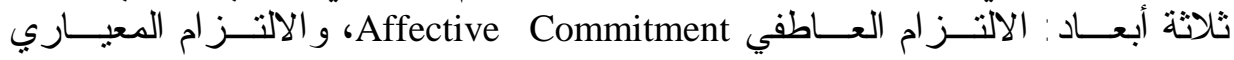
Normative Commitment

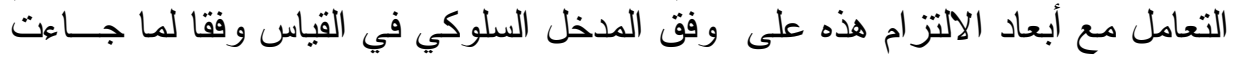

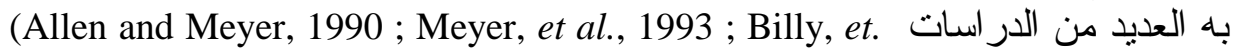
al, 2006 ; Fulford, 2005 ; Kazlauskaite, et al., 2006 ; Lam and Zhang, 2003 ; ليكرت Farzad, et al., 20080 ليكرت الخماسي أيضاً.

$$
\text { أسلوب جمع البيانات }
$$

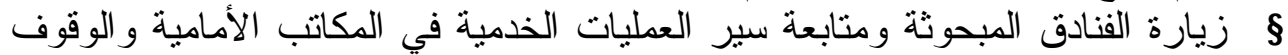

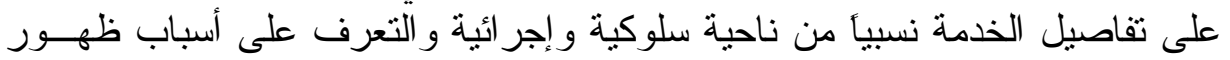

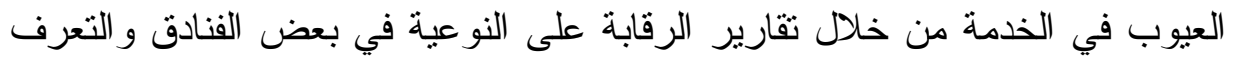

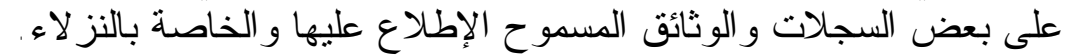

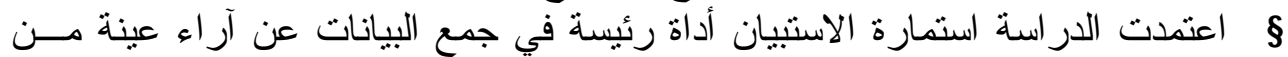

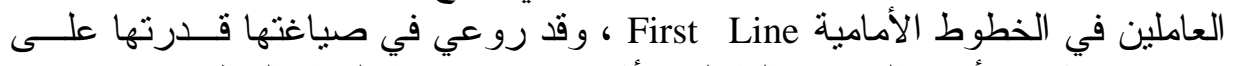

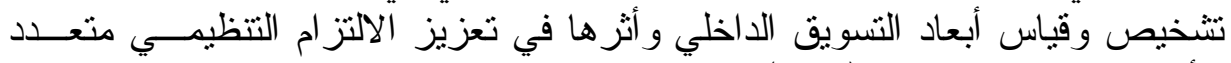

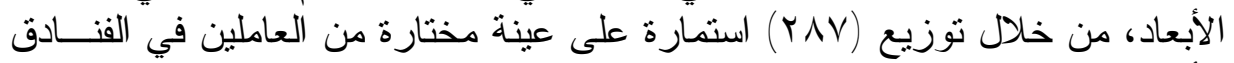

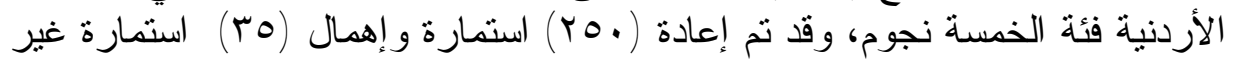
مستوفية للشروط ليكون صافي الاستمار ات التي خضعت للتحليل و الاختبــار ( (10)

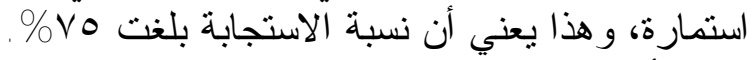

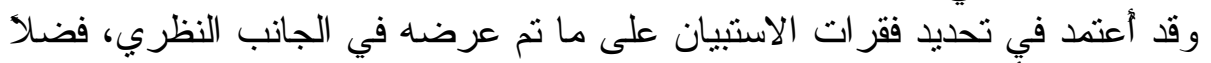

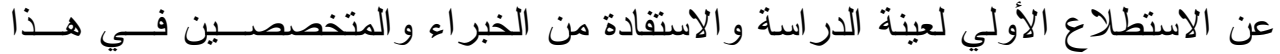

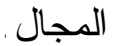

\section{أ. الاختبارات قبل توزيع استمارة الاستبيان - قياس الصدق الظاهري}

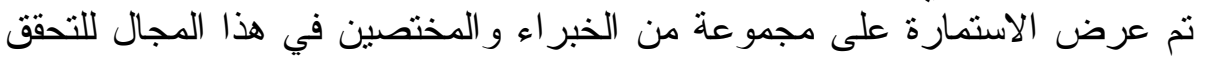

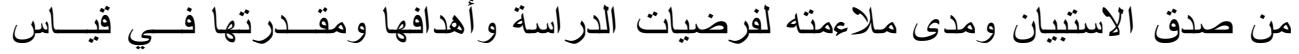


متغير ات الدراسة، وقد أشرت بعض الملاحظات التي أعيرت أهمية كافية، وبذلك حصلت على اتفاق معظم آر اء المحكمين حول صحة لترة فقر اتها.

- ت - تياس ثبات الاستبيان

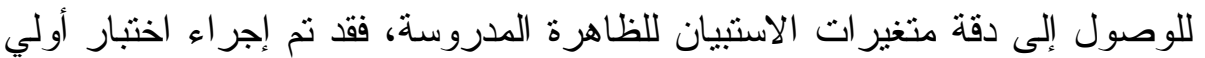

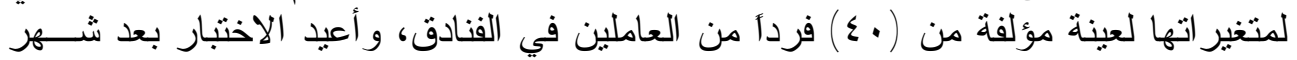

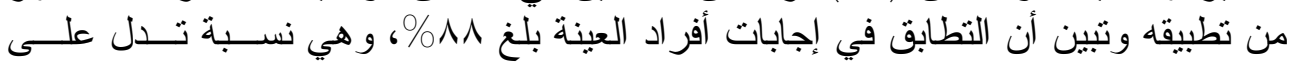

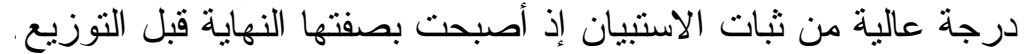

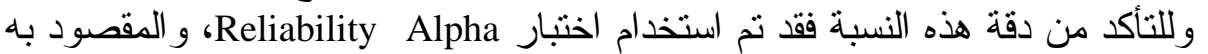

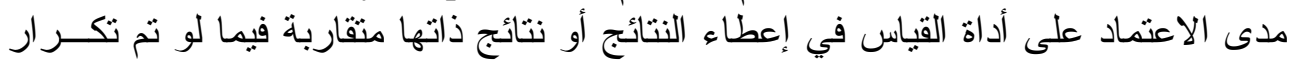
عمليات القياس في ظروف مشابهة على العينة نفسها أو على عينة مماتلة، فقد تم استخدام

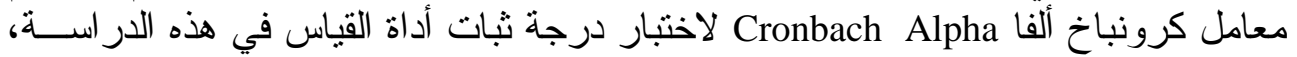

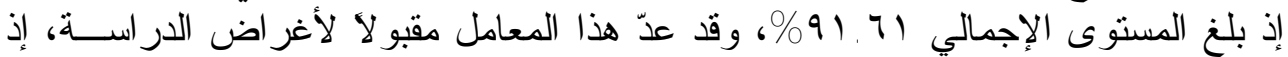

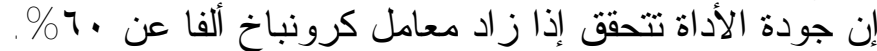

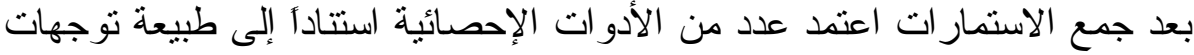
أدوات تحليل البيانات

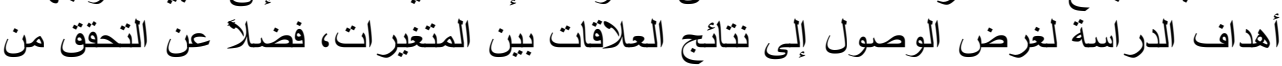

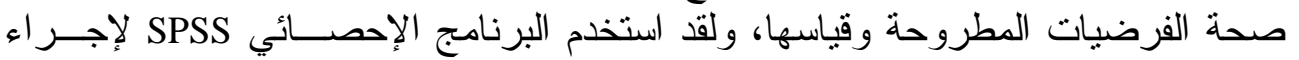

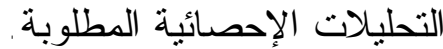

الار اسات السابقة در اسة (Ooncharoen and Ussahawanitchakit , 2009) التي كثف فيها العنفا العلاقة بين

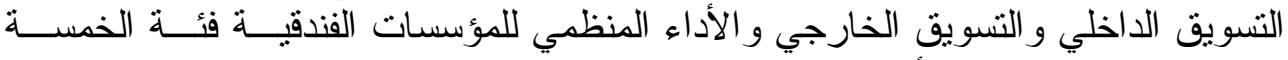

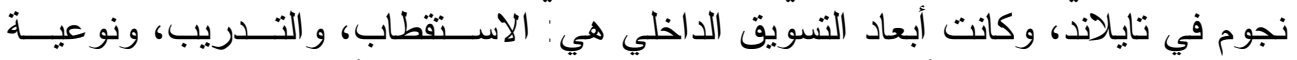

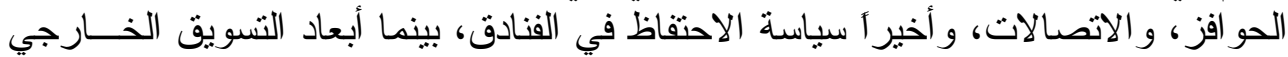

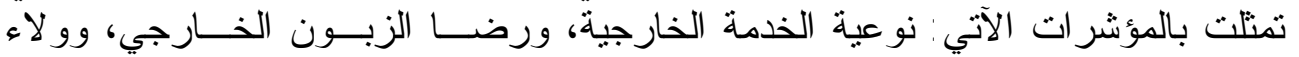

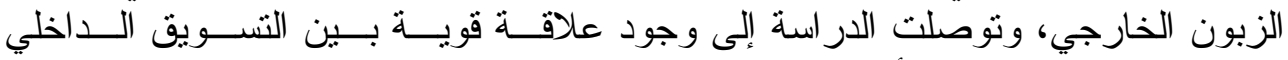

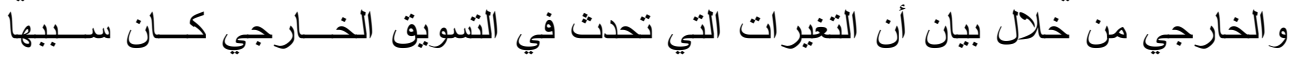

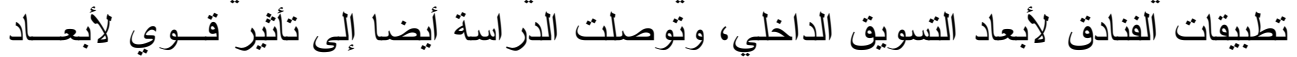

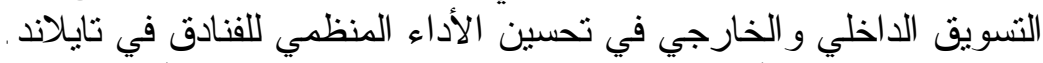

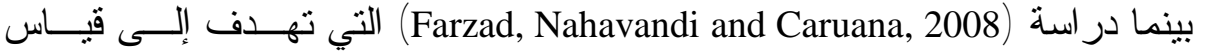
العلاقة بين التسويق الداخلي و الالتز ام التتظيمي متعدد الأبعاد في عينة من الفنــادق فئــة

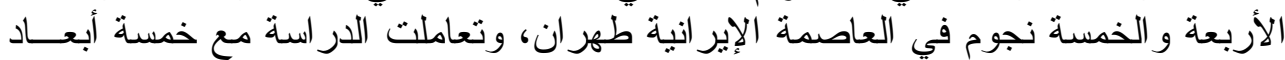

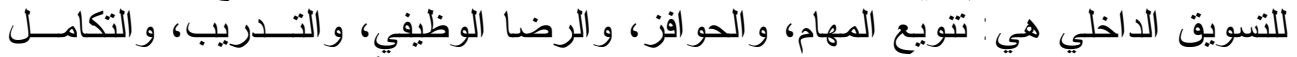

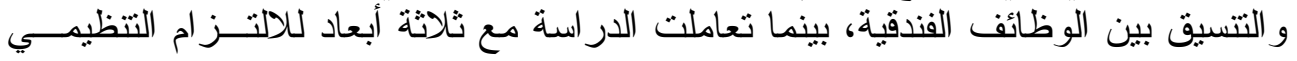

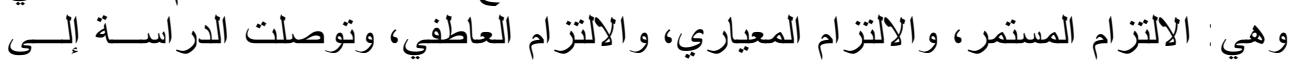

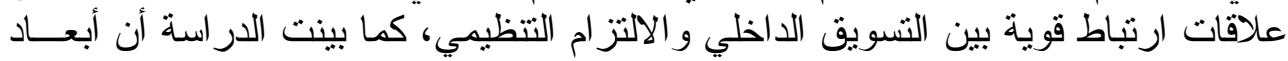


أبو رمان وأمد [

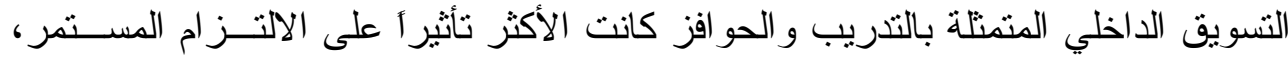

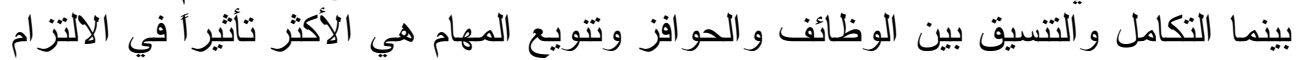

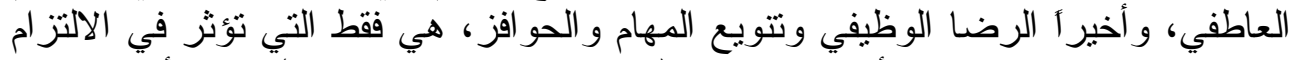

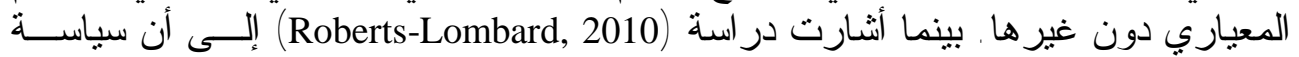

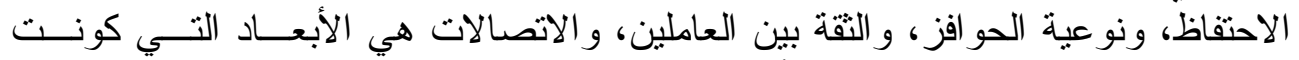

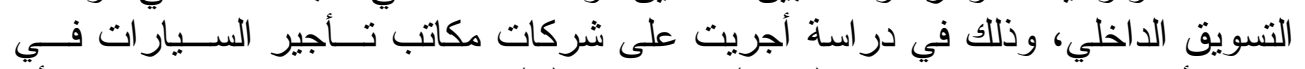

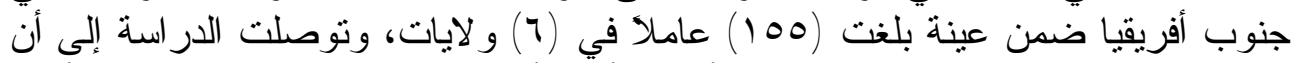

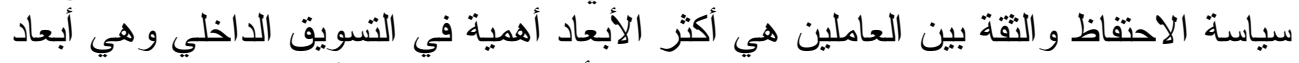

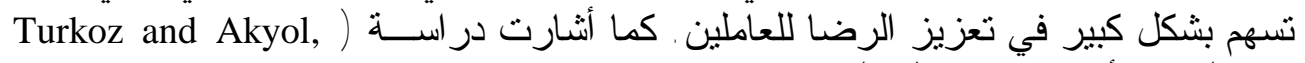

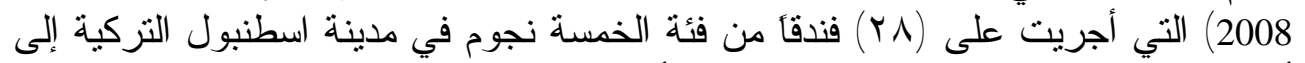

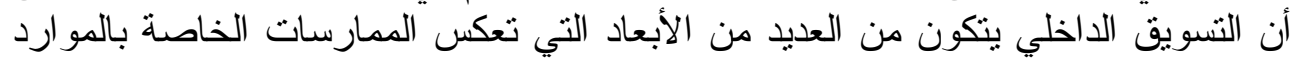

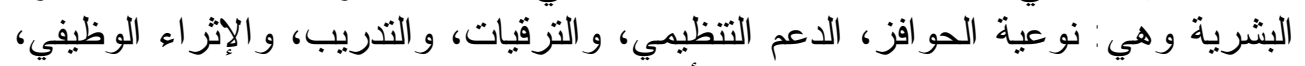

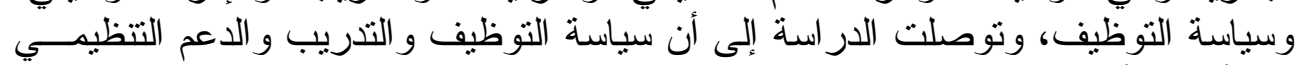

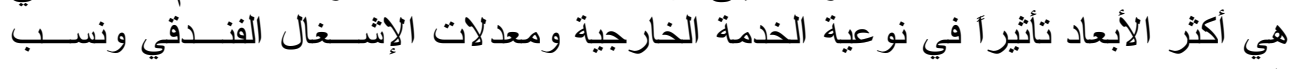

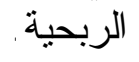

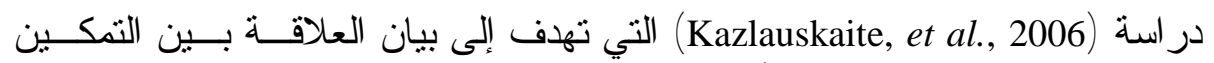

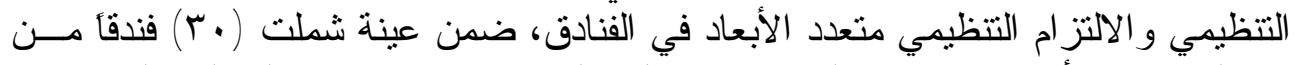

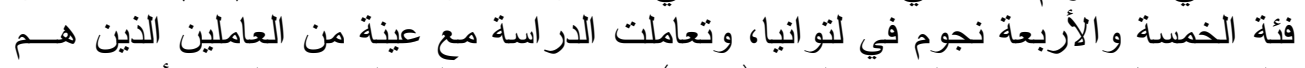

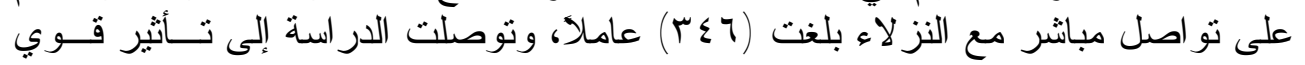

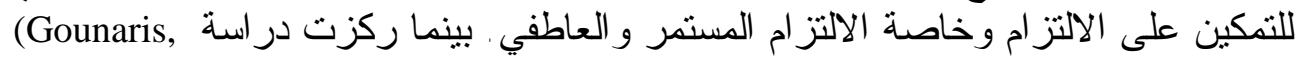

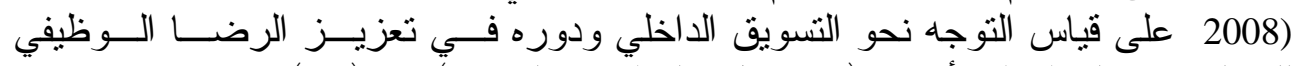

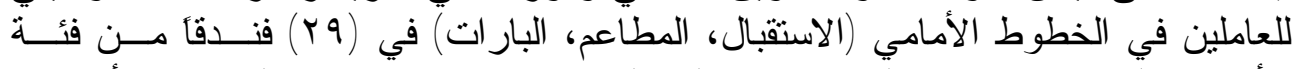

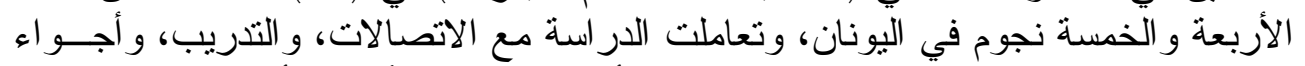

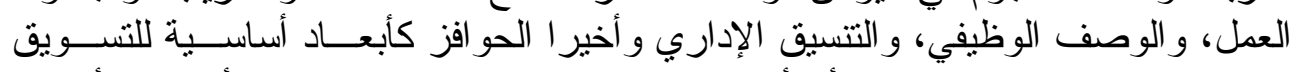

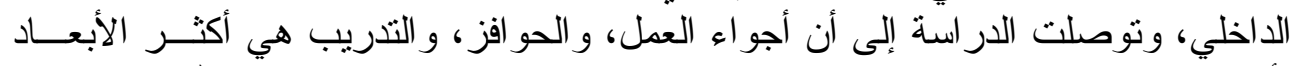

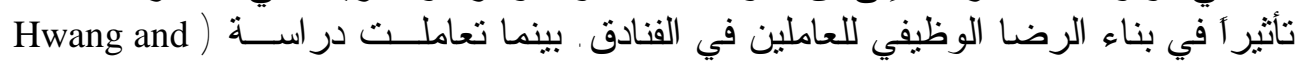

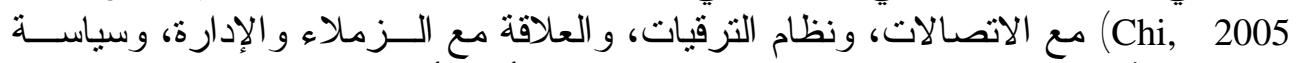

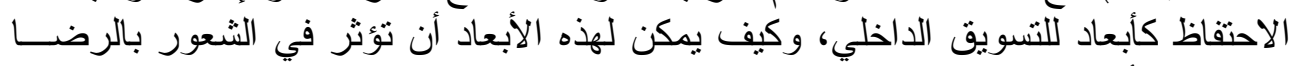

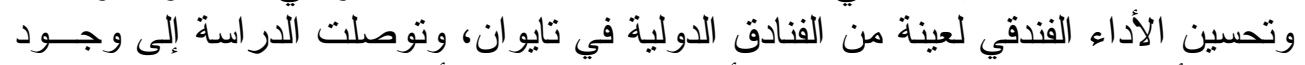

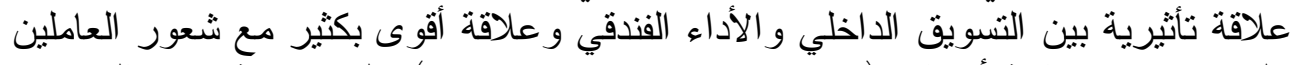

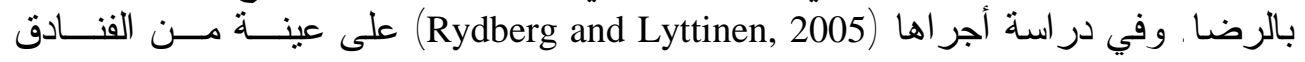

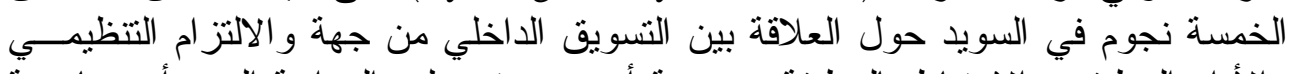

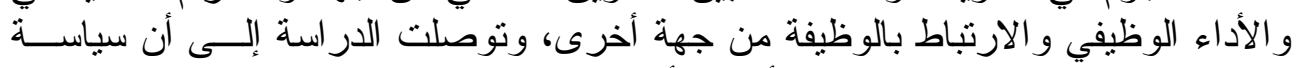

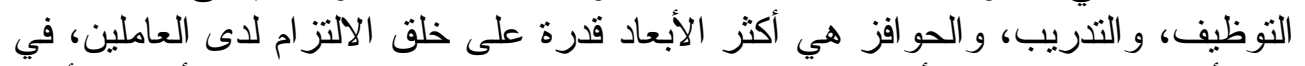

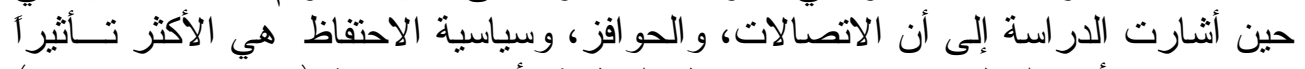

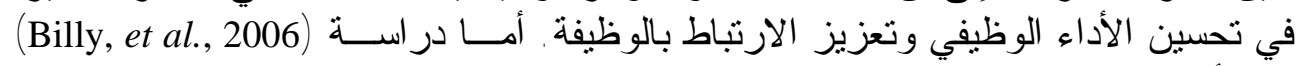

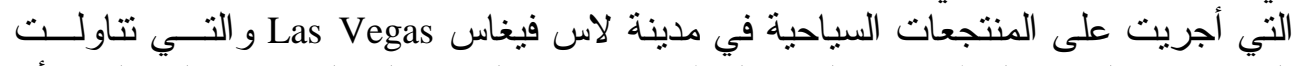

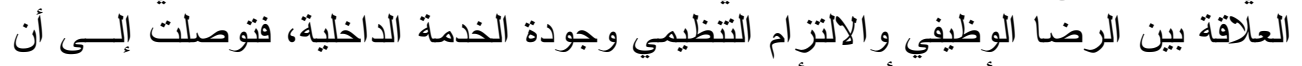

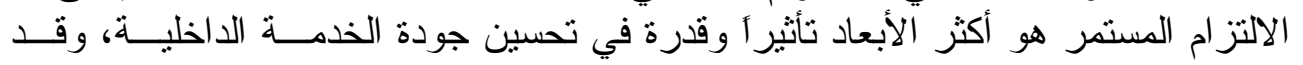


أكدت الدر اسة بأن الدعم التنظيمي، وسياسة الاحتفاظ، ونوعية الحوافز هي أبعاد تـــتبط

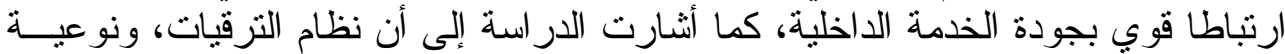

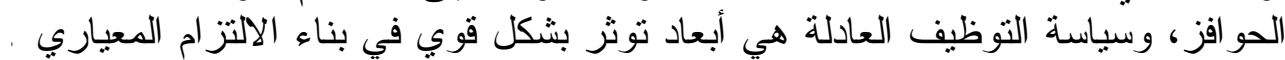

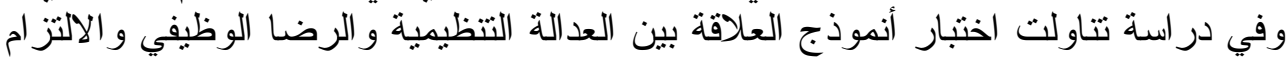

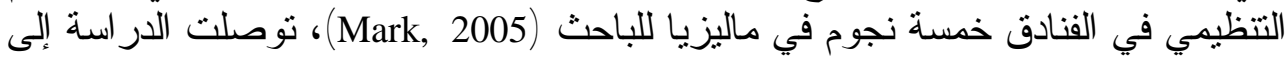

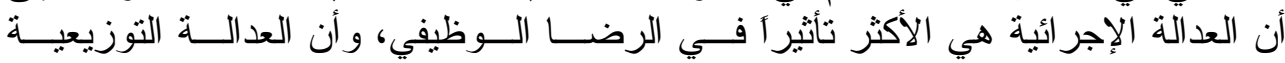

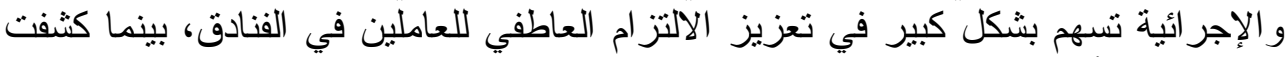

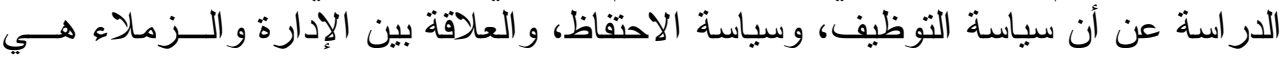

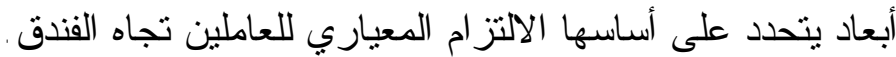

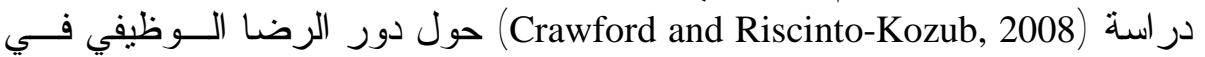
تحسين نو عية الخدمة المقدمة للنز لاء وتعزيز الالتز ام التتظيمي للعاملين فـي المينجعــات

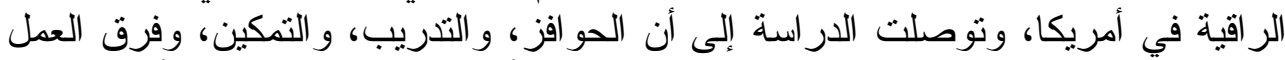

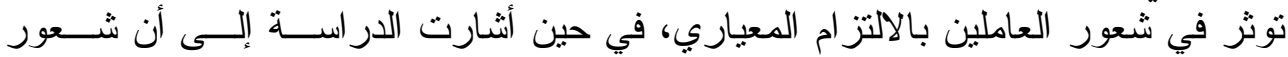

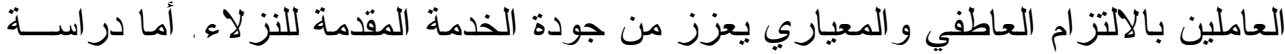
(Lam and Zhang, 2003)

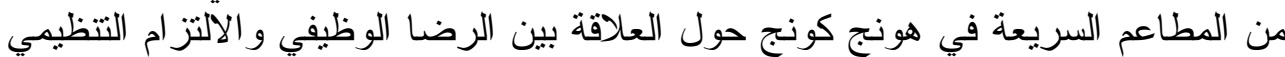

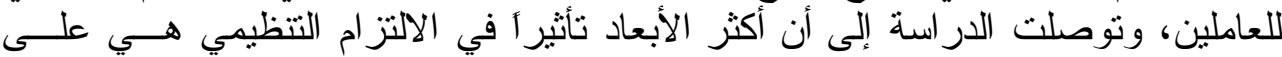

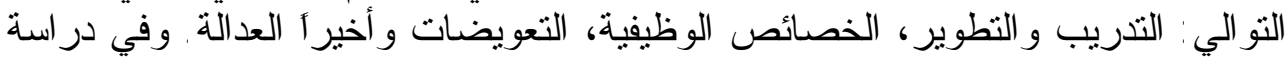

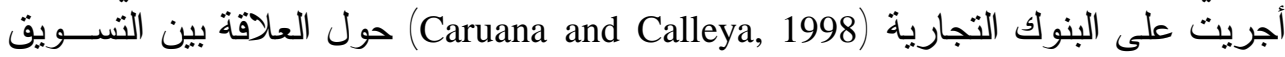

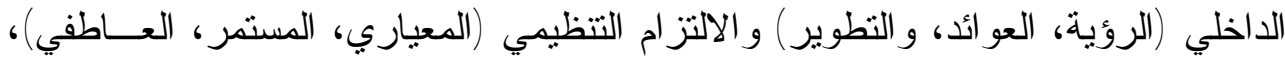
ظهر إلى أن سياسة التطوير و الرؤية هي أبعاد توثر في الالتز ام المعياري التئي للعاملين، بينما

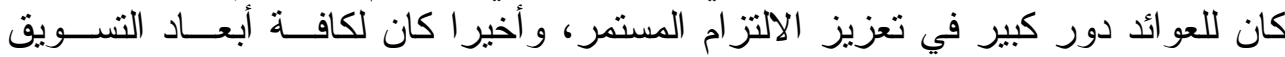

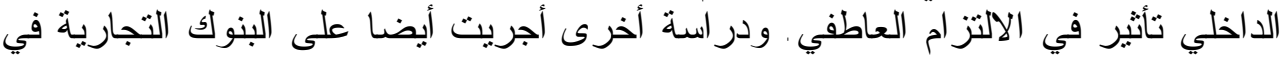

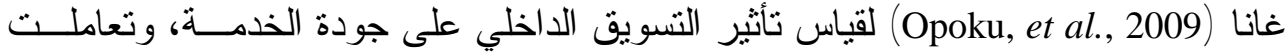

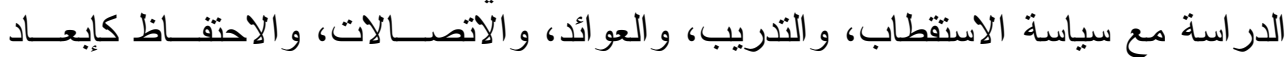

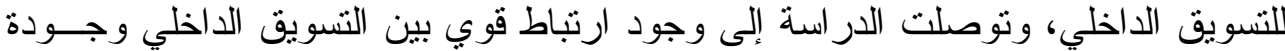

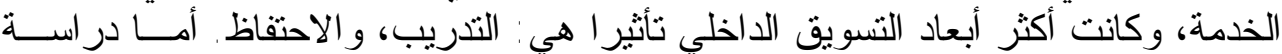

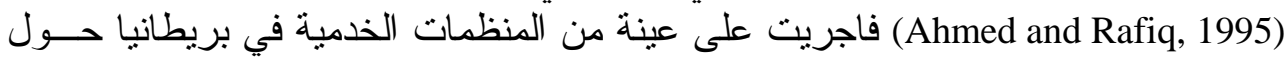

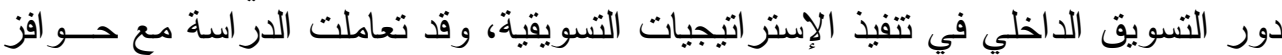

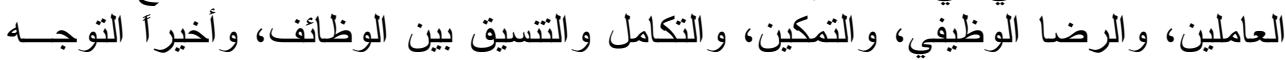

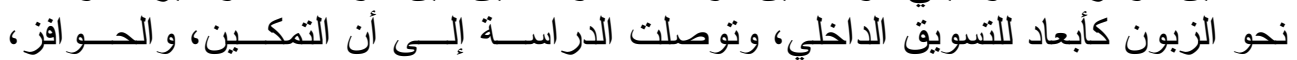

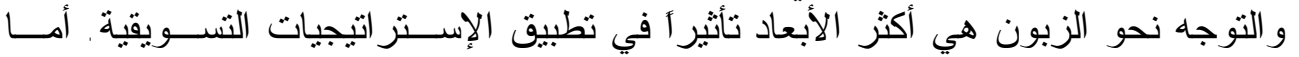

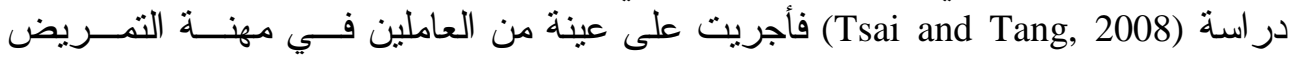

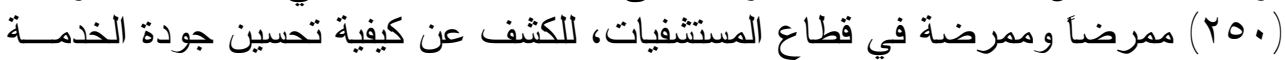

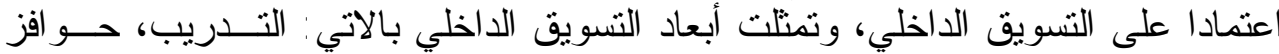

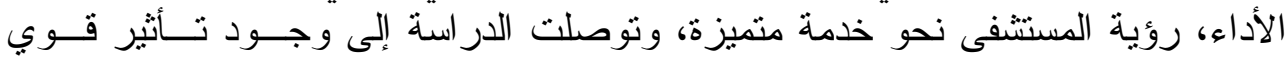

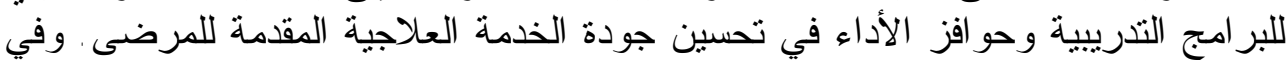

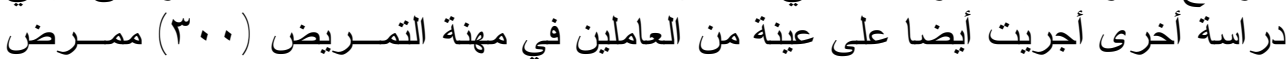


أبو رمان وأمد]ـ[0]

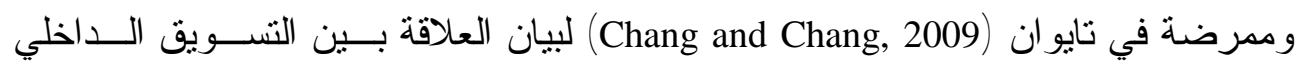

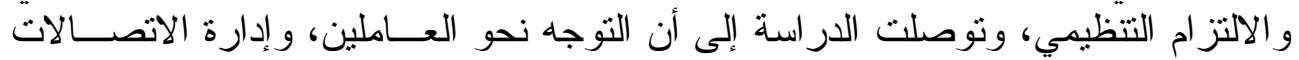
الداخلية هي أكثر الأبعاد قدرة على بناء الالتز ام التنظيمي.

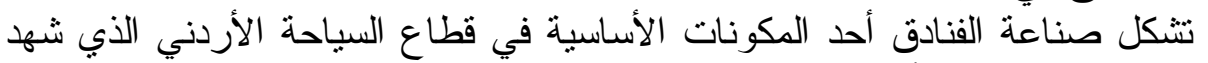

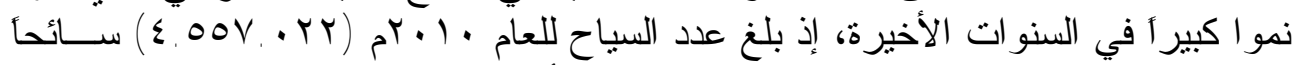

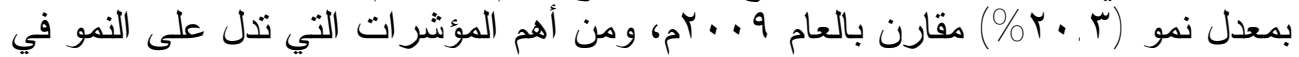

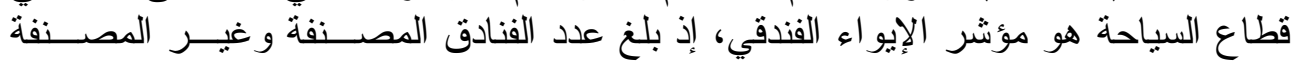
في (\&V)

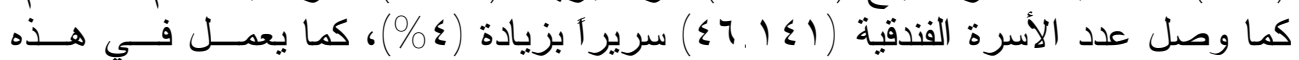

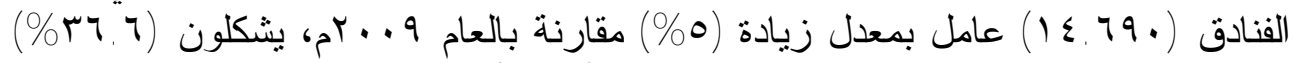

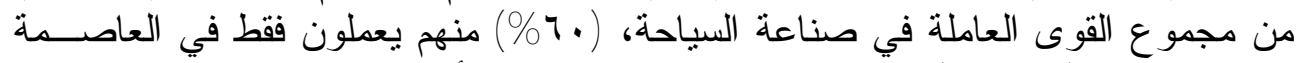

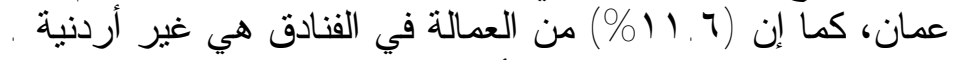

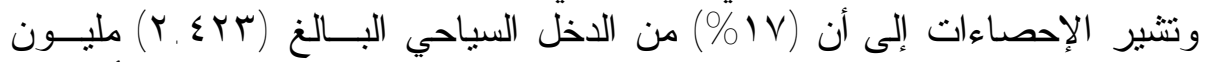

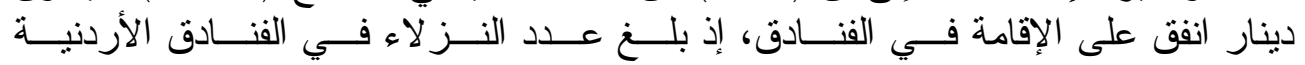

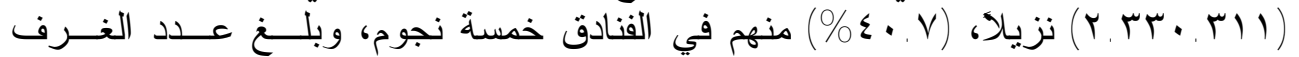

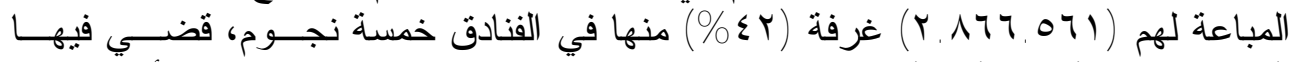

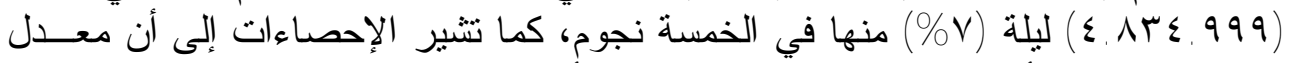

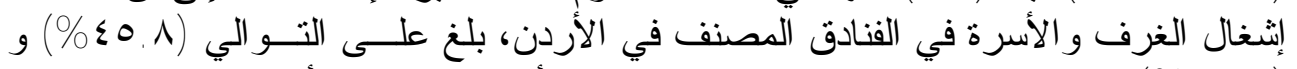

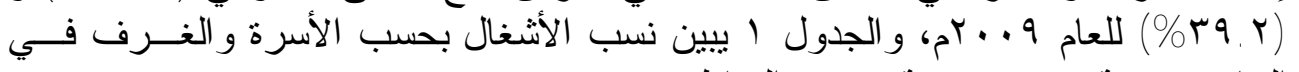

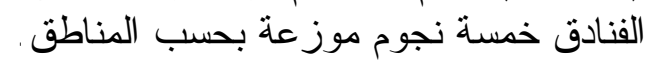

\begin{tabular}{|c|c|c|c|}
\hline \multirow{2}{*}{\multicolumn{2}{|c|}{$\left(a^{r} \cdot 9\right)$}} & إثغال الغرف والأسرة في الفنادر & \\
\hline & & المناطق & \\
\hline 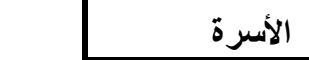 & الغرف & & \\
\hline$\% \leftleftarrows 1.0$ & $\% 04 . Y$ & عمان & \\
\hline$\% \leqslant \wedge .9$ & $\% \leqslant 9$ & العقبة & \\
\hline$\% 07 . r$ & $\% 00.1$ & البتز اء & \\
\hline$\% \circ \varepsilon . r$ & $\% 0 \leq, Y$ & البحر الميت & \\
\hline$\%$ \% . ร & $\% 0 \leq .7$ & الإجمالي على مستوى الأردن & \\
\hline
\end{tabular}

\section{التسويق الاخلي: المفاهيم والأبعاد مفهوم التسويق الدئ: الداخلي وأهميته والابعاد}

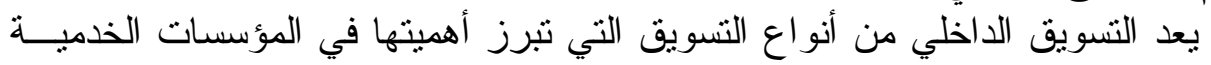

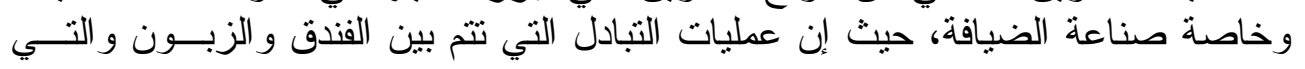
ركز عليها التسويق من الناحية التقليدية لا تكفي لوحدها بل لات لا بد من الاهتمام بالعـاملين، 


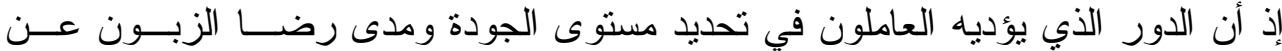

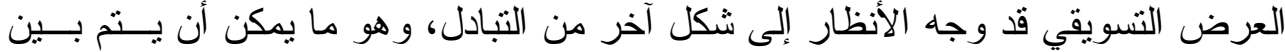

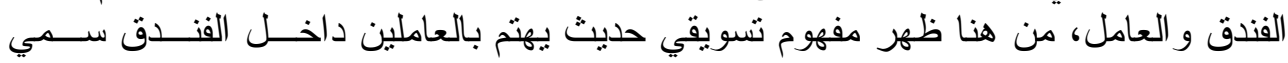

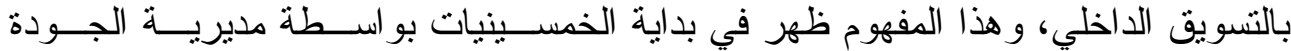

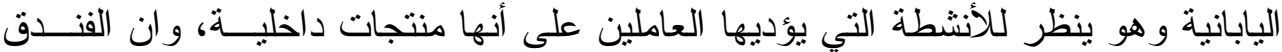

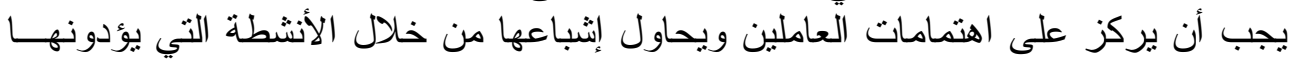

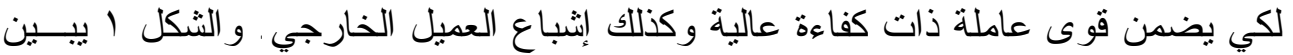
أنو أع التسويق في المنظمات الفندقية.

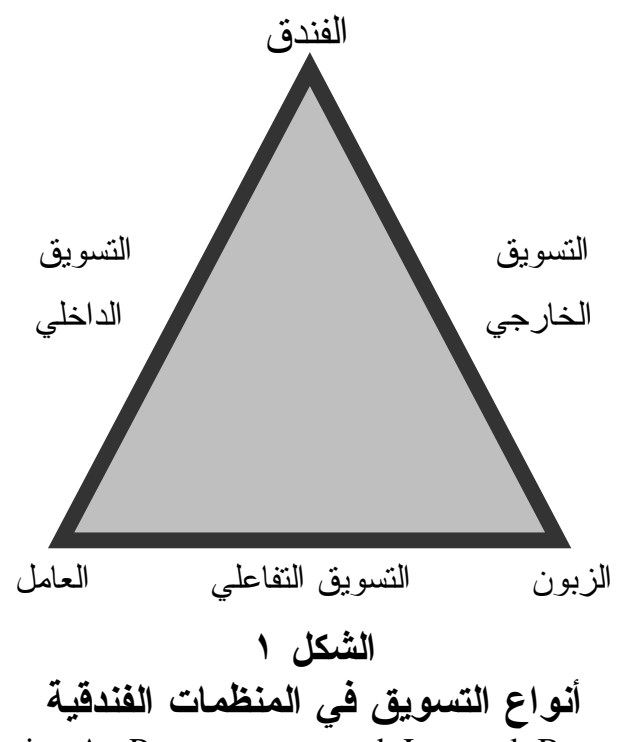

Source: Zeithaml, Valarie, A. Parasuraman, and Leonard Berry. (1985). Program and Strategy in Service Marketing, Journal of Marketing, Vol. 49, PP33-46.

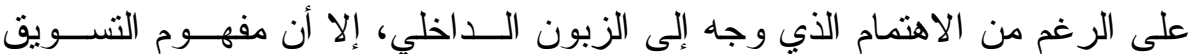

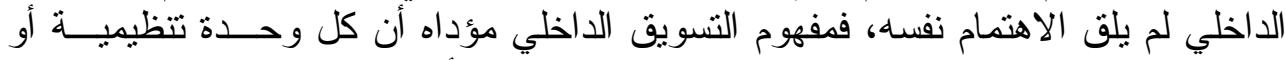

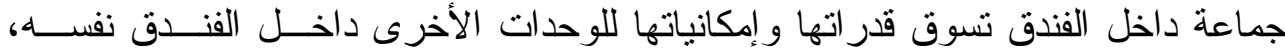

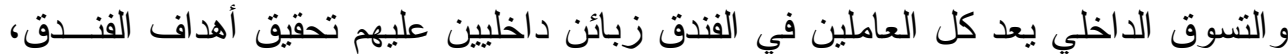

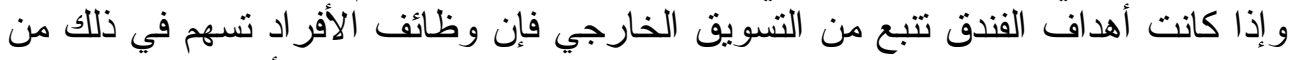

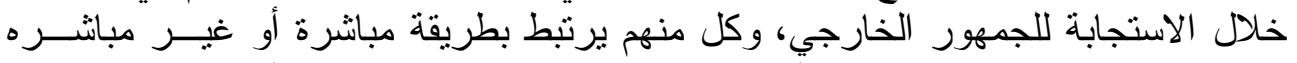

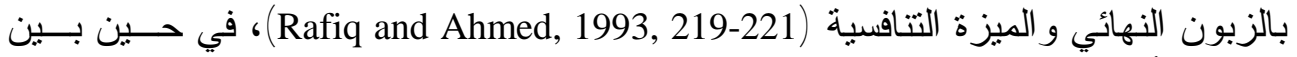

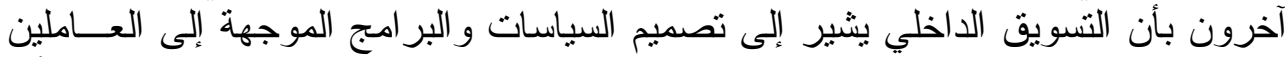

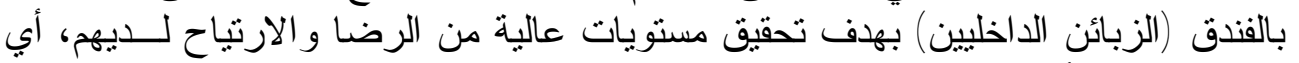

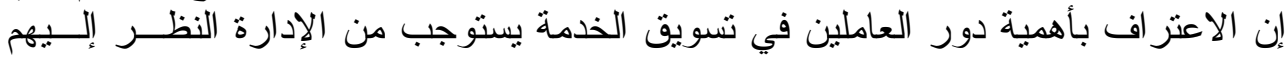

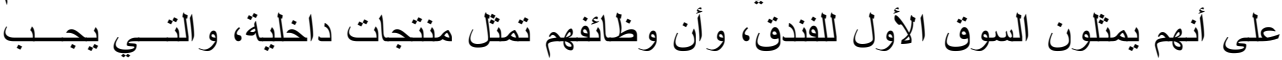


[00]

تصميمها وتطوير ها بما يتفق وحاجاتهم ور غباتهم ومن ثم زيادة درجة رضاهم و الجــدول r بيين أهم التعاريف التي تتاولت التسويق الداخلي من قبل عدد من الباحثين.

\begin{tabular}{|c|c|}
\hline \multicolumn{2}{|c|}{ 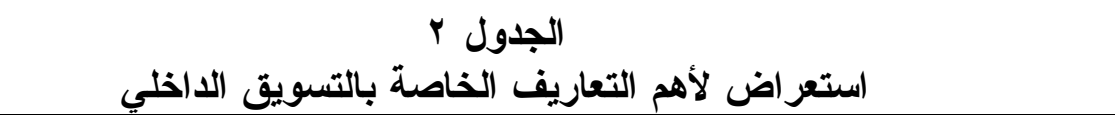 } \\
\hline الباحثين / السنة & مفهوم التسويق الاخلي \\
\hline Farzad, et al, 2008 & 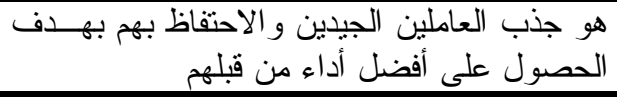 \\
\hline Caruana and Callaya, 1998 & 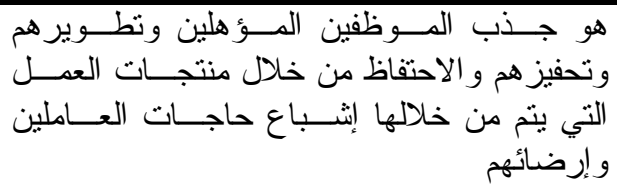 \\
\hline Chang and Chang, 2009 & 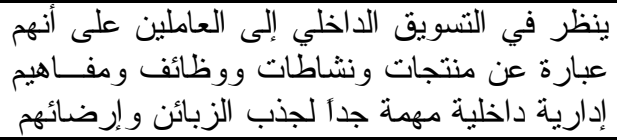 \\
\hline Kotler , 2006 & الزبائن بأفضية تدريب طريقة ممكنية وتحفيز هم بهدف خدمة \\
\hline Zeithaml and Bitner, 2006 & 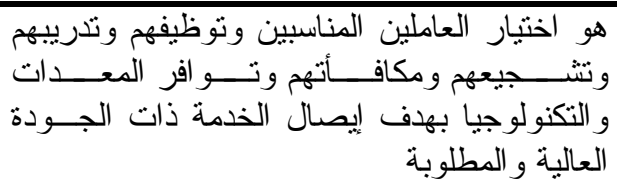 \\
\hline
\end{tabular}

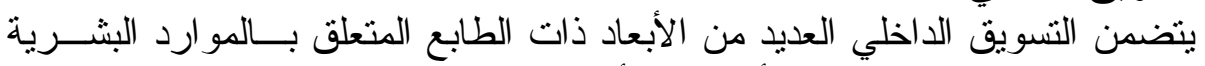

\section{أبعاد التسويق الاخلي}

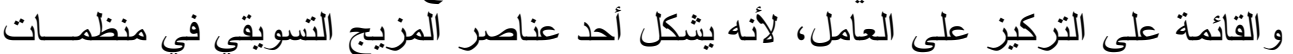

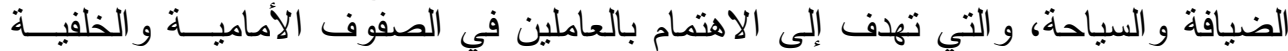

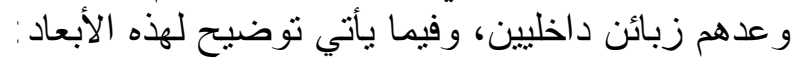

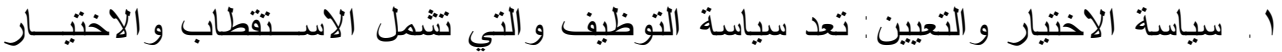

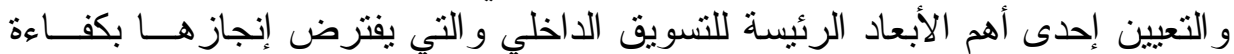

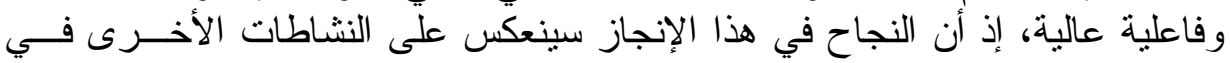

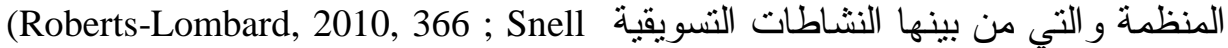
(and White, 2009, 196-201 ) إذ أن الخطأ و التساهل في سياسة التعيين في منظمات التهات

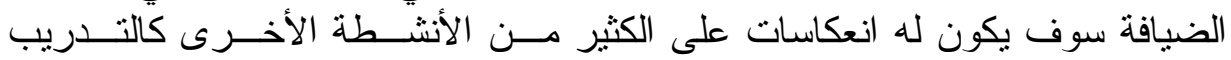

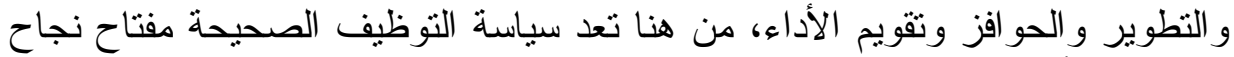

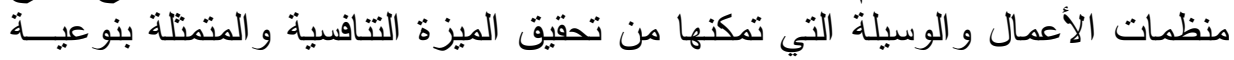

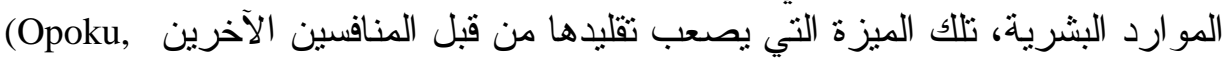

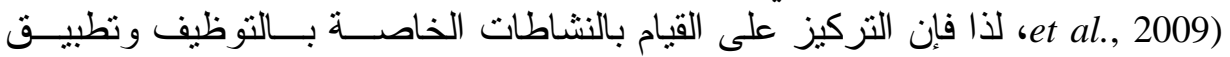
إجر اءات التوظيف بعدالة سوف تمكن منظمات الضيافة من اختيار العمالة المناســبة

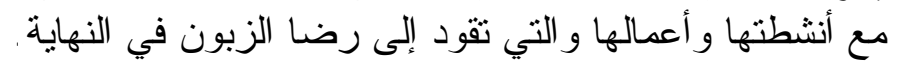




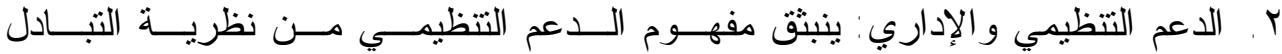

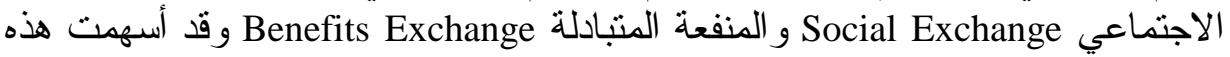

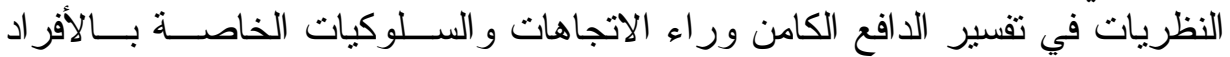

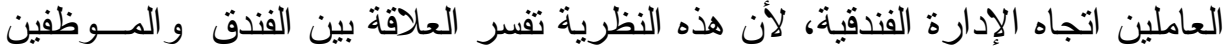

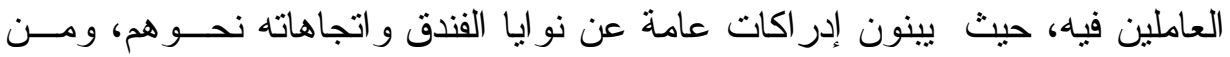

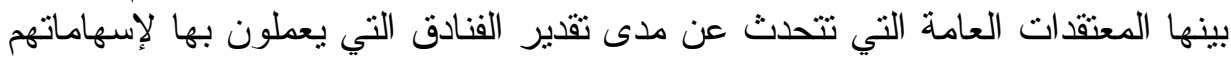

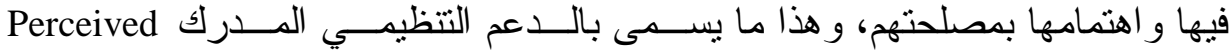
Ooncharoen and Ussahawanitchakit, 2009, 25-27; ) Organizational Support

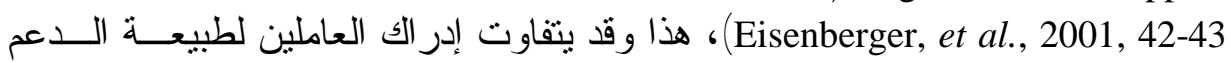

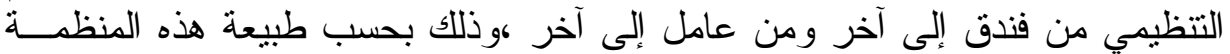

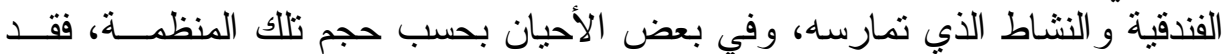

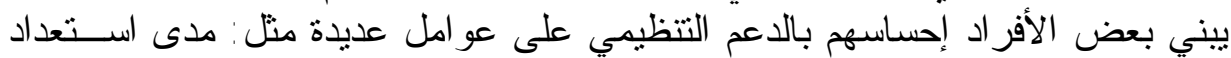

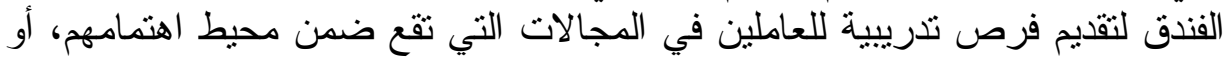
تتجيعهم على التطوير الوظيفي والترقيات الوظيفية، أو إتاحة الفرصة للقئ للعاملين لأجل

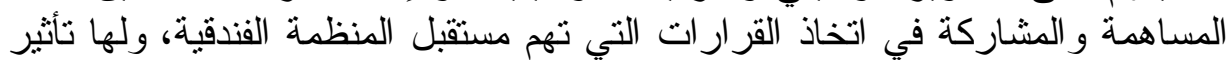

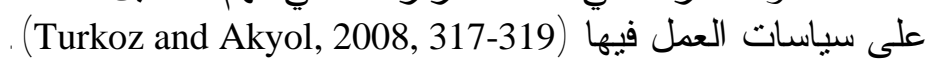

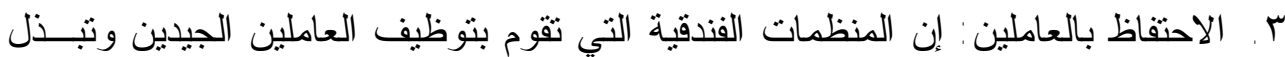

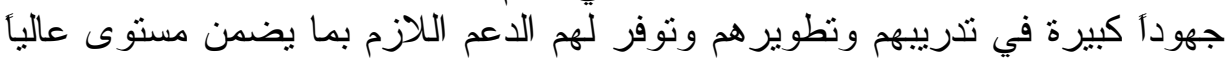

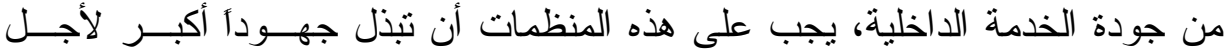

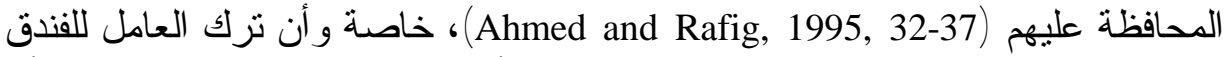

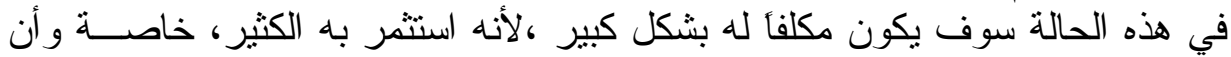

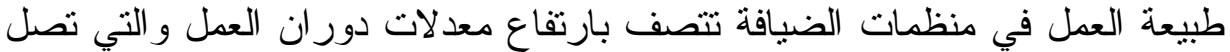

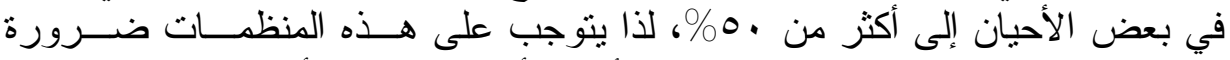

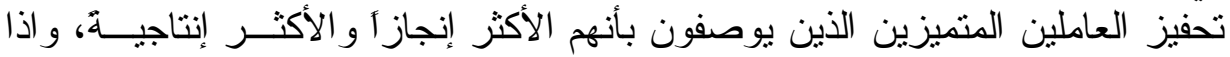

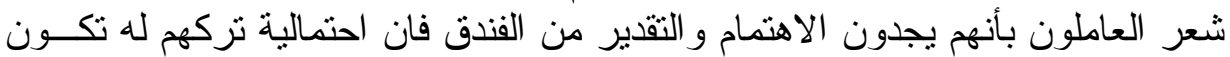

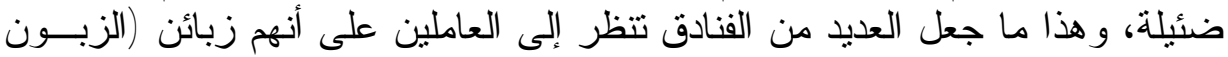

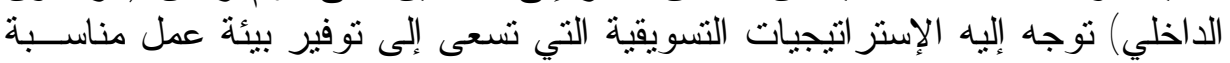

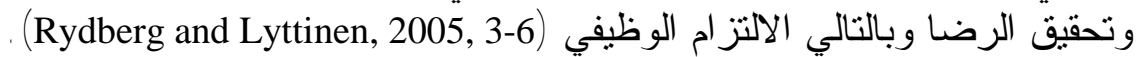

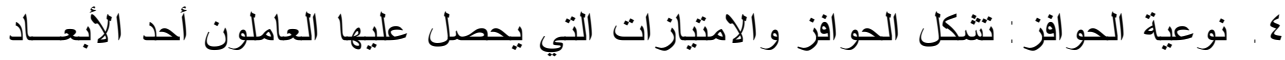

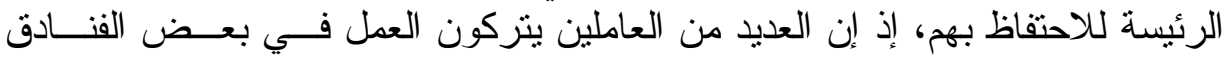

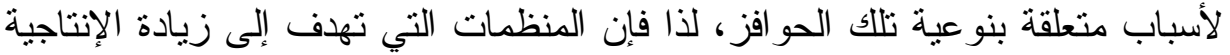

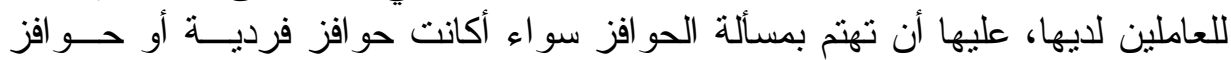

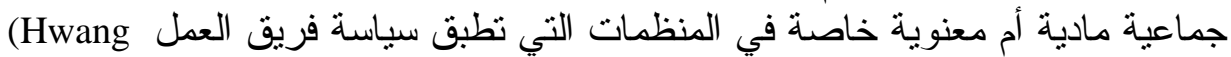

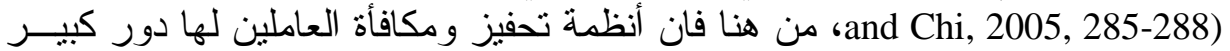

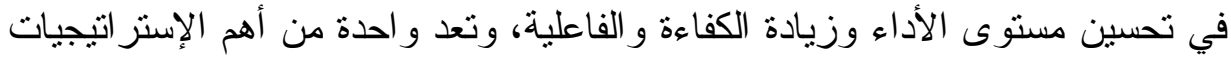

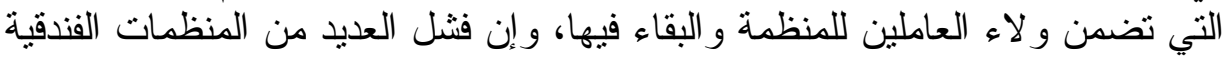
في تقديم خدمة ذات جودة عالية يعود إلى عدم تو افر أنظمة فعالة لتحفيز العاملين. 


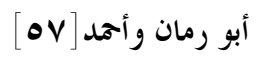

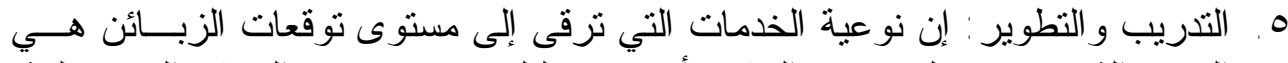

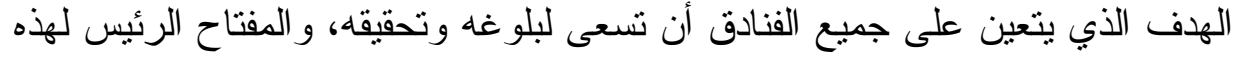

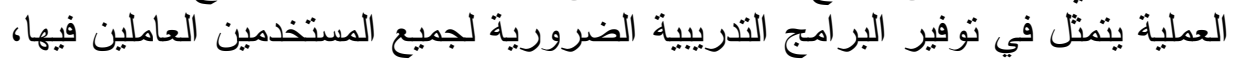

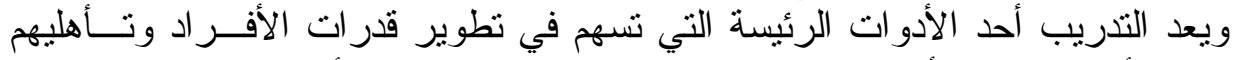

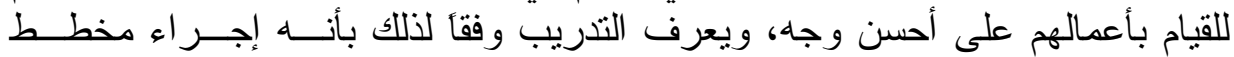

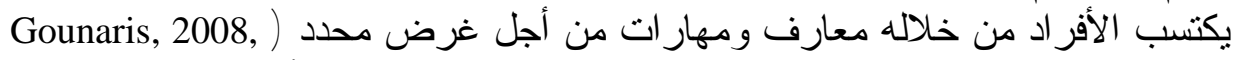

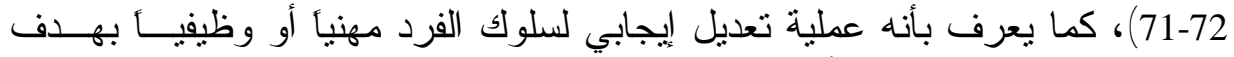

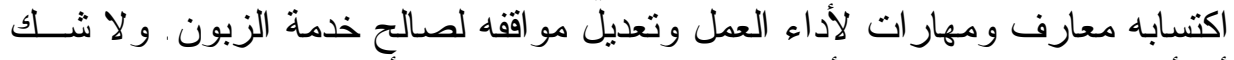

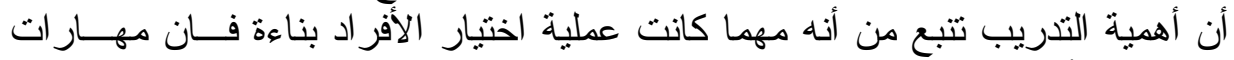

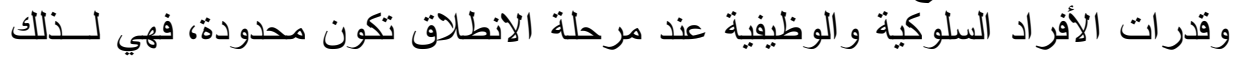

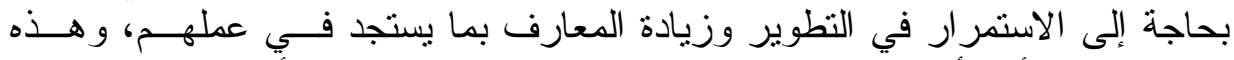

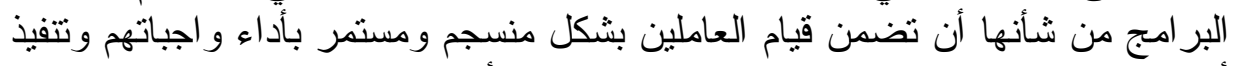

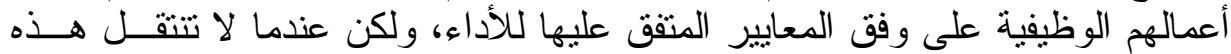

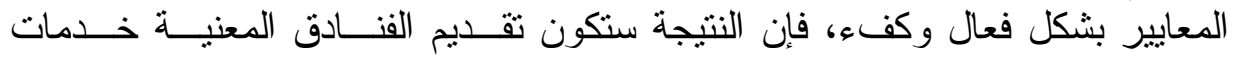

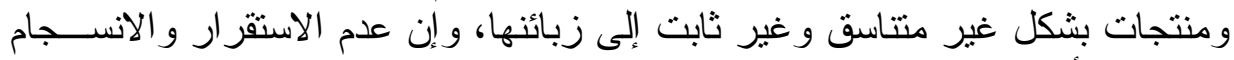

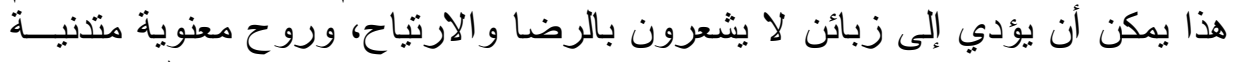

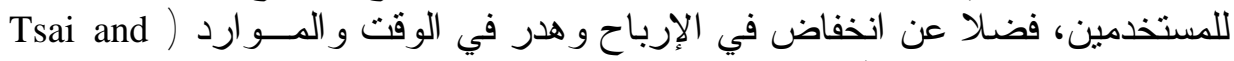

. (Tang, 2008, 1118-1119

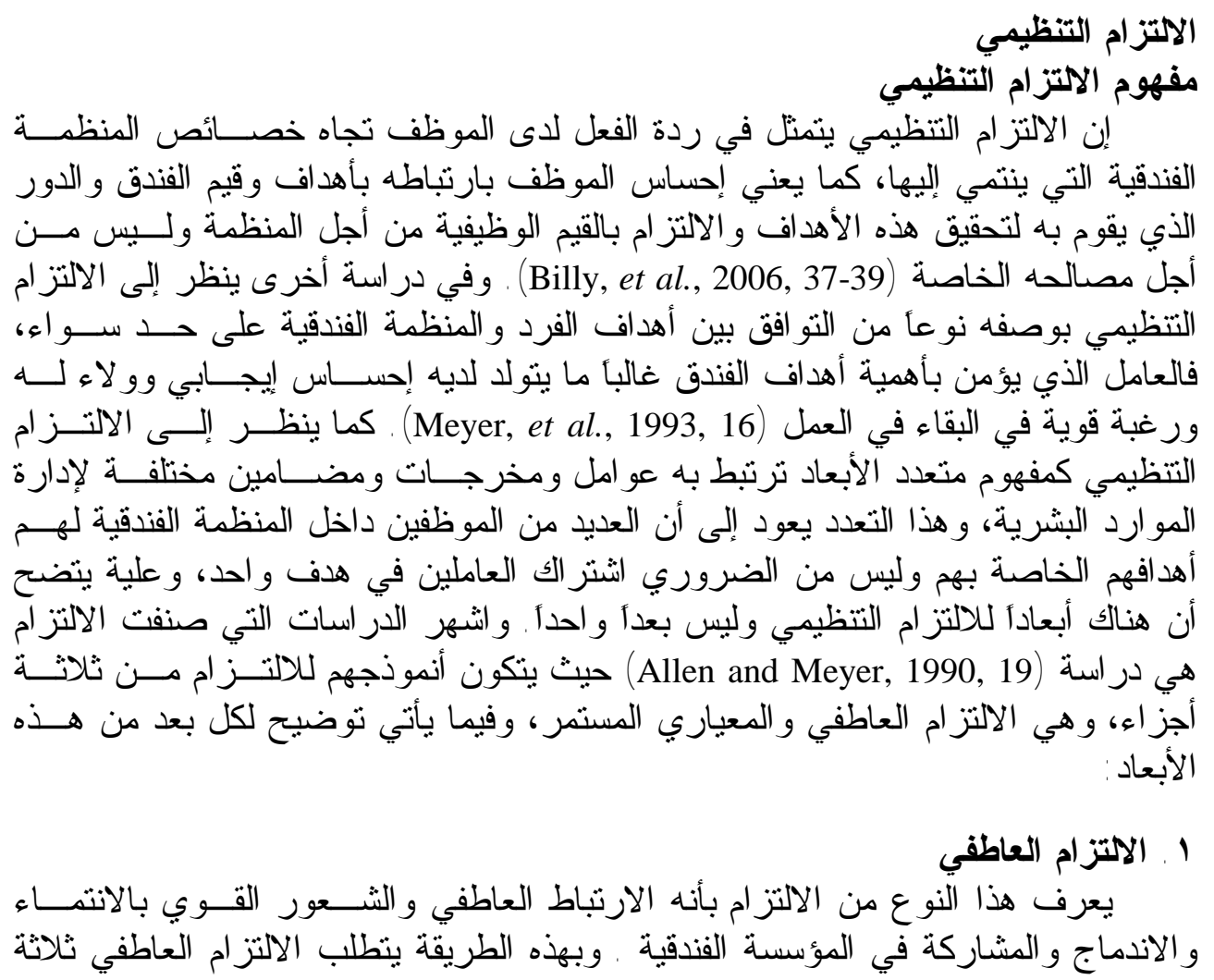




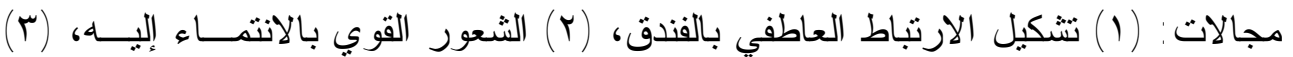

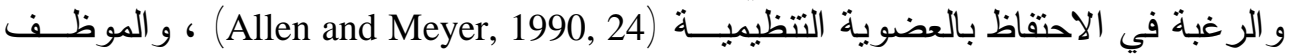

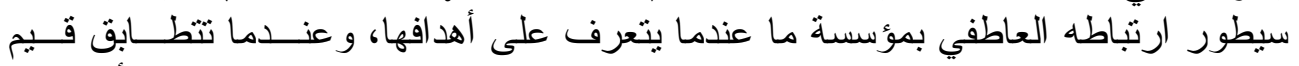

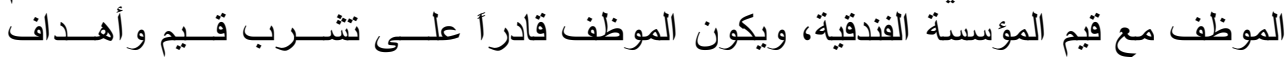

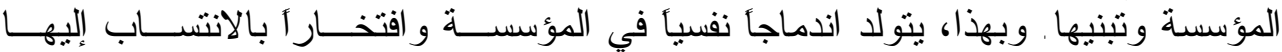

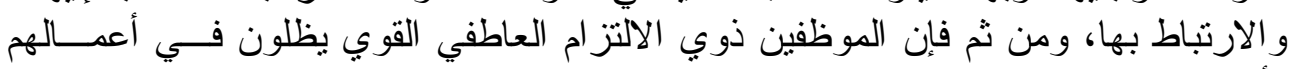

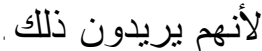

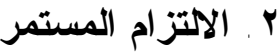

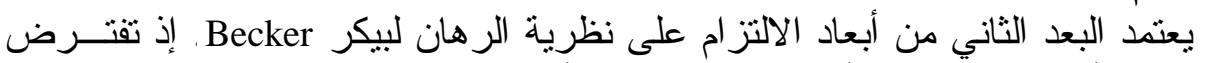

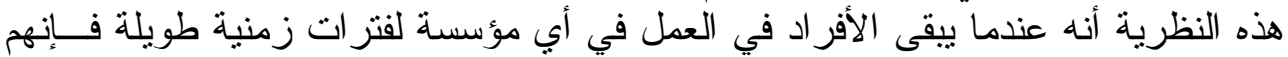

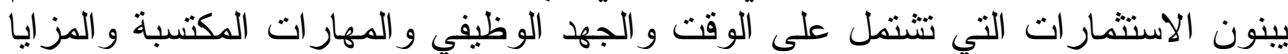

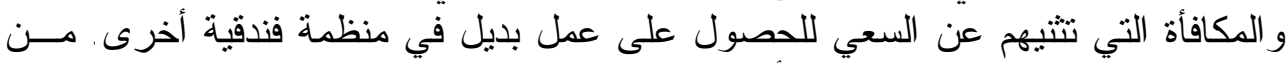

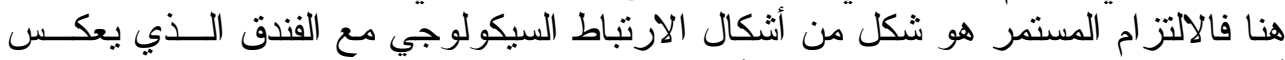

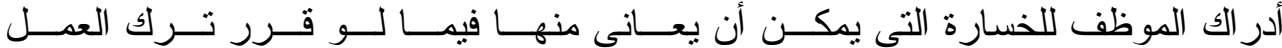
(Kazlauskaite, et al., 2006, 300-304)، و عليه فإن الالنز ام المستمر يتطلب من الموظف

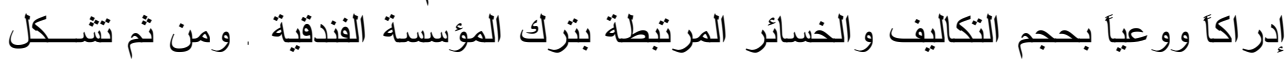

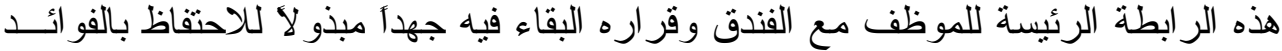

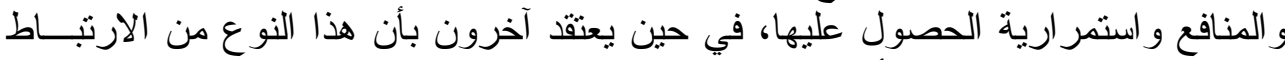

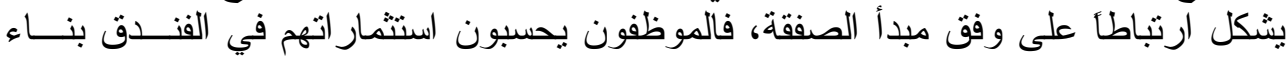

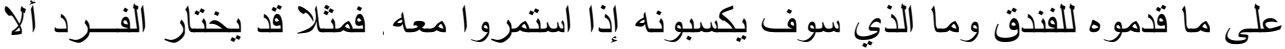

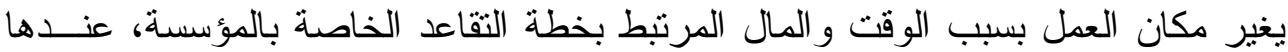

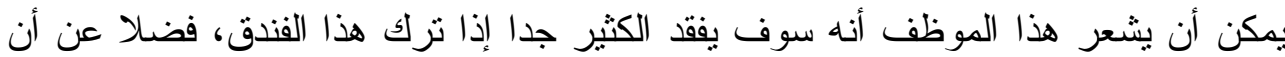

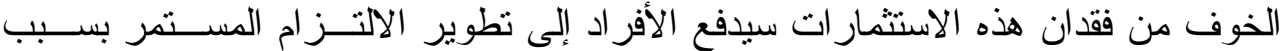

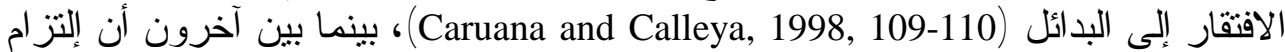

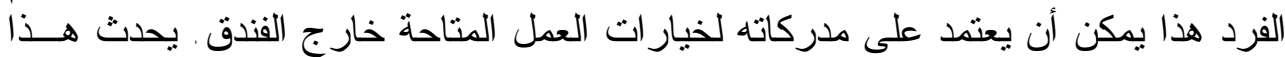

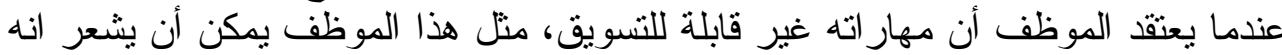

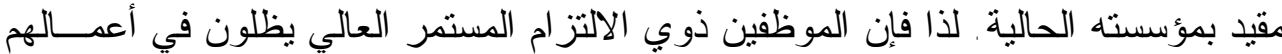

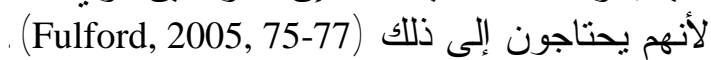

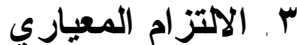

البعد الثالث من الالتزام التتظيمي هو الالتزام المعياري و الذي يعكس الإحساس في

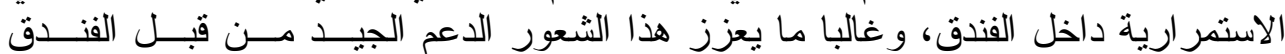

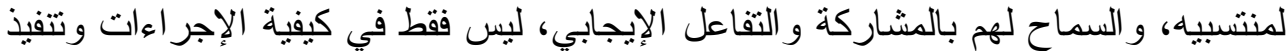

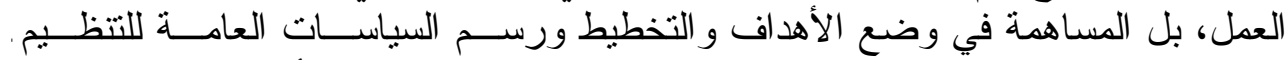

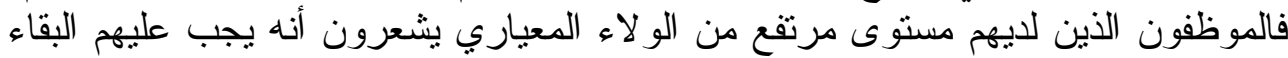

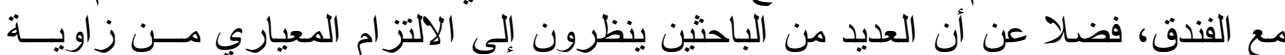

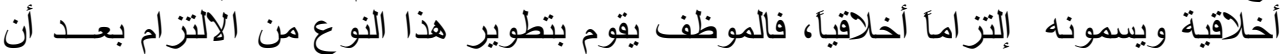

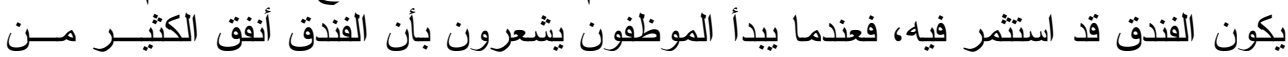

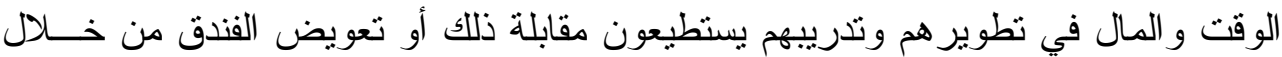




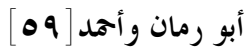

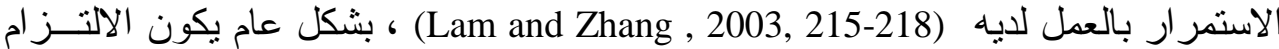

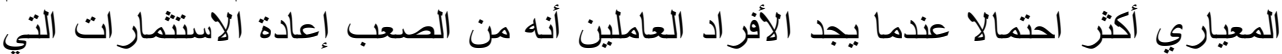

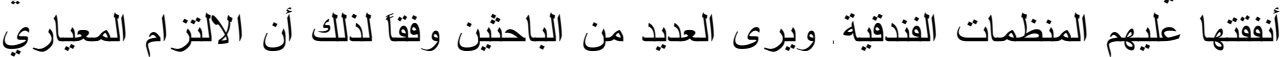

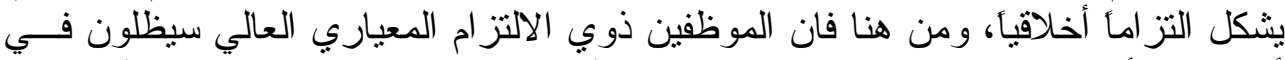
أعمالهم، لأنهم يشعرون بان عليهم الثزاما بذللك (Allen and Meyer, 1990, 22-23).

الفرضية الرئيسية: Ho "ليس هناك علاقلاقة تأثيرية بين إستراتيجية التسويق الـــاخلي

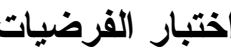

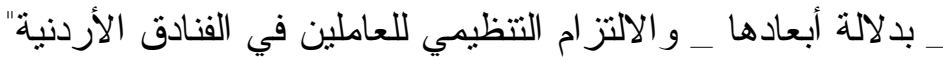

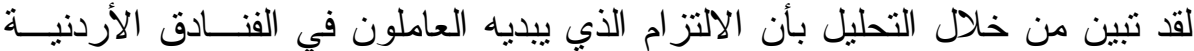

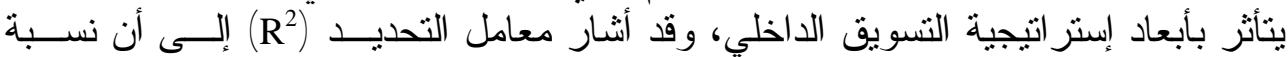

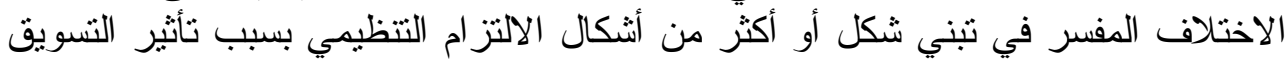

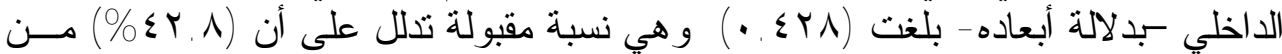

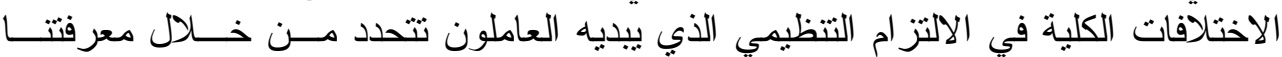

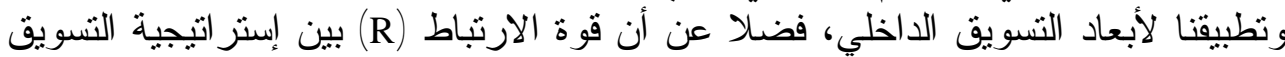

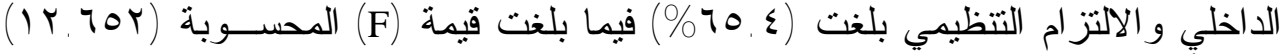

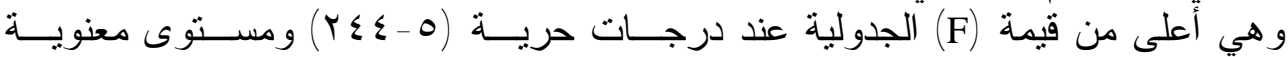

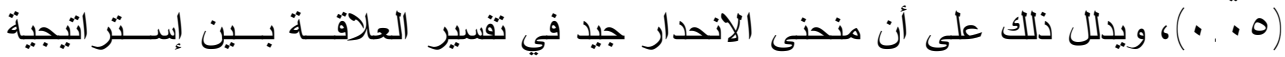

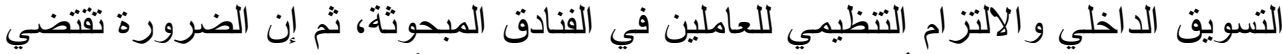

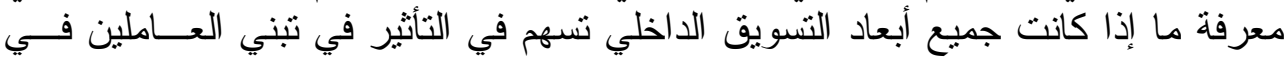

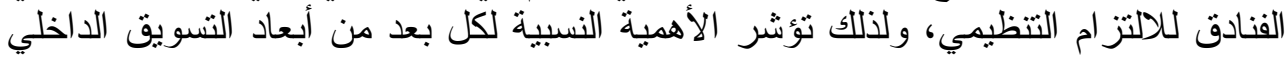

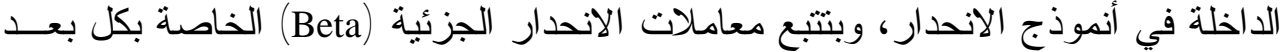

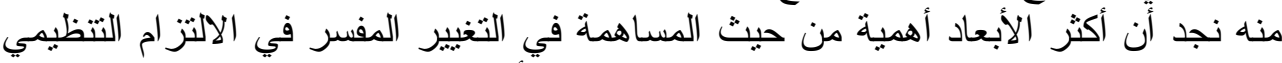

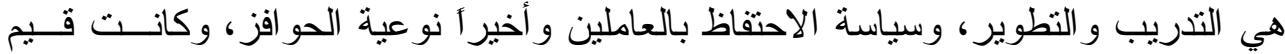

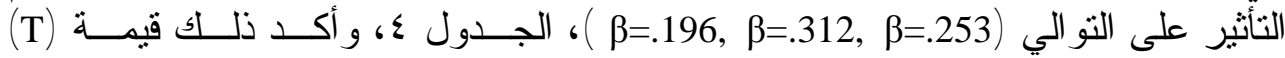

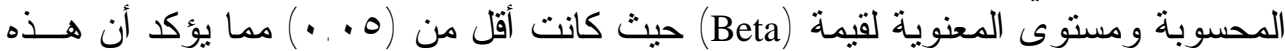

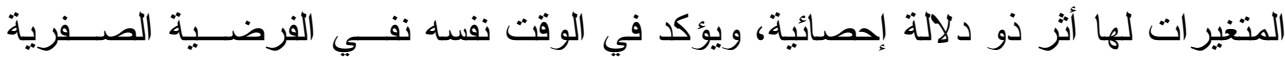

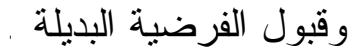

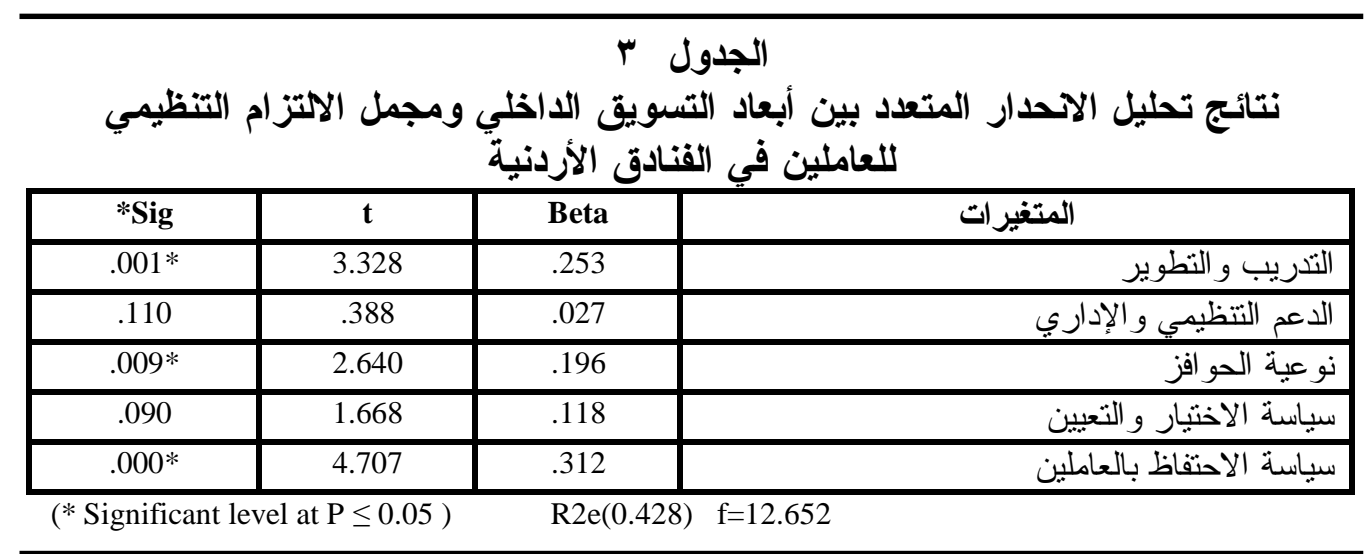




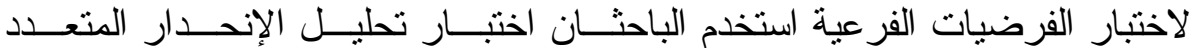
Multiple Regression

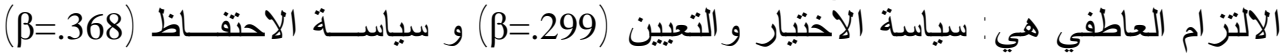

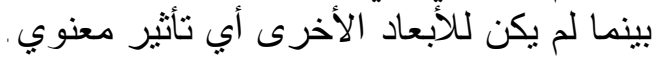

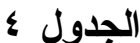

نتائج تحليل الآحدار المتعدد بين التسويق الداخلي والاتتزام العاطقي للعاملين في القنادق الأردنية الأخي

\begin{tabular}{|c|c|c|c|}
\hline Sig $\quad *$ & $\bar{t}$ & Beta & المتغير ات \\
\hline $.000^{*}$ & 4.614 & .299 & سياسة الاختيار و التعبين \\
\hline .137 & 1.491 & .120 & التدريب و التطوير \\
\hline .277 & 1.090 & .079 & نوعية الحو افز \\
\hline .187 & 1.322 & .099 & الدعم التتظيمي و الإداري \\
\hline $.000 *$ & 5.682 & .368 & سياسة الاحتفاظ \\
\hline
\end{tabular}

$\left(\mathrm{R}^{2}=.335 ; \mathrm{F}=5.788\right) *$ Significant level at $\mathrm{P} \leq 0.05$

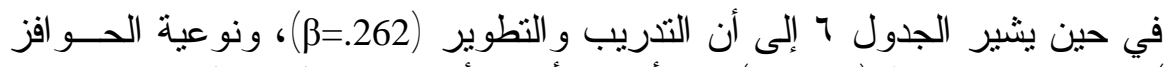

(3=.212)، وسياسة الاحتقاظ (210.210) هي أكثر الأبعاد نأثير آ في الالتز ام المستمر .

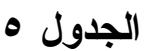

نتائج تحليل الاحدار المتعدد بين التسويق الداخلي والالتزام المستمر للعاملين في القنادق الأردنية الفين

\begin{tabular}{|c|c|c|c|}
\hline Sig $\quad *$ & $\mathbf{t}$ & Beta & المتغير اد \\
\hline .497 & .681 & .052 & سياسة الاختيار و التعيين \\
\hline $.001 *$ & 3.218 & .262 & التذريب و التطوير \\
\hline $.008^{*}$ & 2.681 & .212 & نوعية الحو افز \\
\hline .878 & .154 & .012 & الدعم التتظيمي و الإداري \\
\hline $.003^{*}$ & 2.966 & .210 & سياسة الاحتفاظ \\
\hline
\end{tabular}

$(\mathrm{R} 2=.348 ; \mathrm{F}=4.876) *$ Significant level at $\mathrm{P} \leq 0.05$

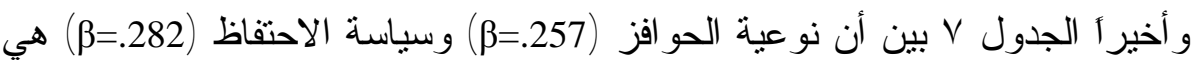

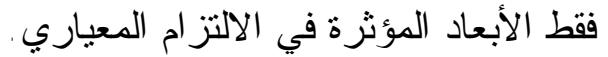




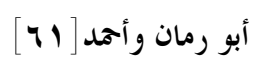

\begin{tabular}{|c|c|c|c|}
\hline \multicolumn{4}{|c|}{ 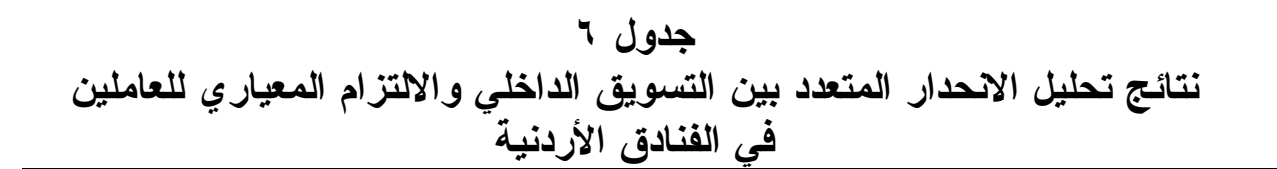 } \\
\hline Sig & $\overline{\mathbf{t}}$ & Beta & المتغير \\
\hline .251 & 1.150 & .086 & سياسة الاختيار و التعبين \\
\hline .097 & 1.666 & .147 & التّريب و التطوير \\
\hline $.000 *$ & 3.543 & .257 & نوعية الحو افز \\
\hline .826 & $.220-$ & $.018-$ & الدعم التتظيمي و الإداري \\
\hline $.000^{*}$ & 3.893 & .282 & سياسة الاحتفاظ \\
\hline \multicolumn{4}{|c|}{$\left(\mathrm{R}^{2}=.226 ; \mathrm{F}=7.654\right)^{*}$ Significant level at $\mathrm{P} \leq 0.05$} \\
\hline \multicolumn{4}{|c|}{ 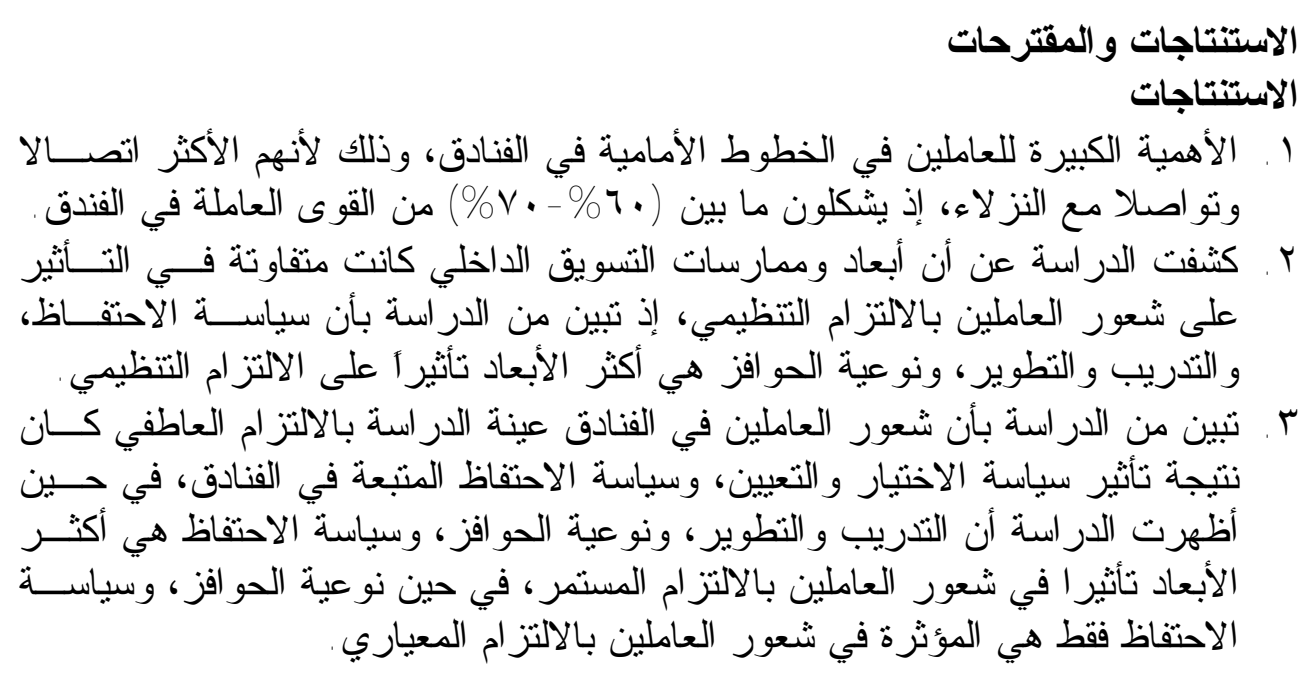 } \\
\hline
\end{tabular}

المقترحات

1. ضرورة الاهتمام بسياسة التوظيف بكافة مكوناتها (الاستقطاب و الاختيار و التعيين) في

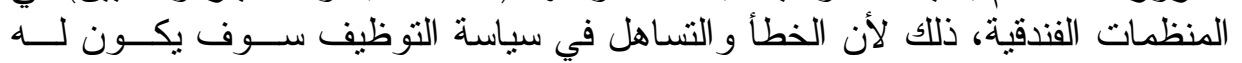

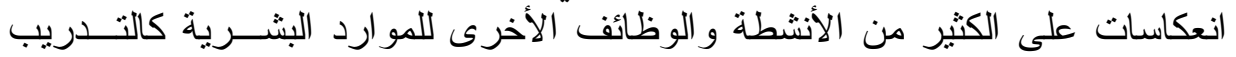

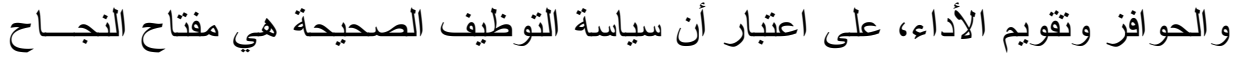

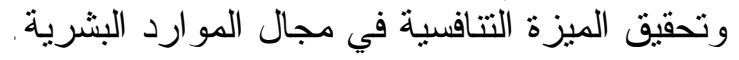

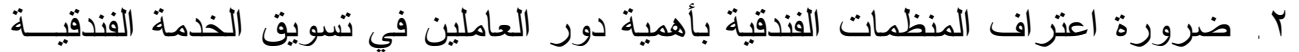

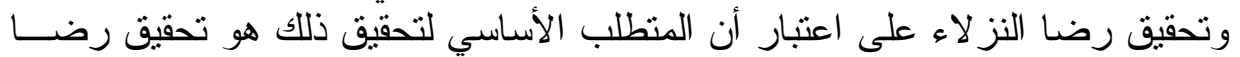

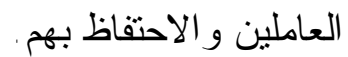

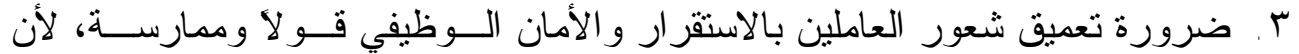

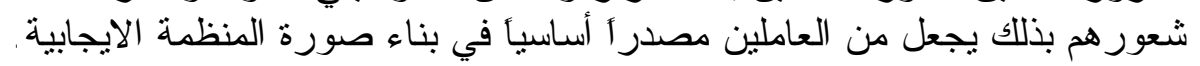




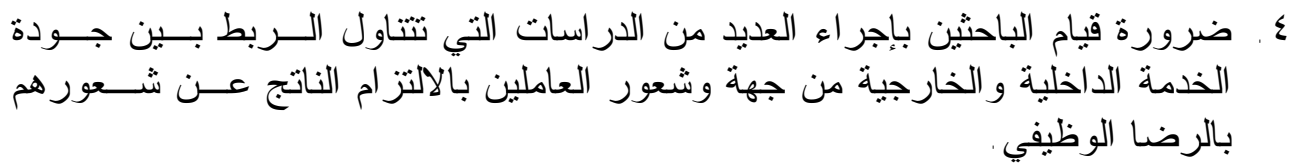

Refrence

1. Tsai, Yafang and Tang, Ta-Wei,2008,"How to Improve Service Quality: Internal Marketing as a Determining Factor", Total Quality Management, Vol. 19, No. 11,.Available at: www.emeraldinsight.com.

2. Caruana, Albert and Calleya, Peter,1998,"The Effect of Internal Marketing on Organizational Commitment Among Retail Bank Managers", International Journal of Bank Marketing, Vol. 16, No. 3, Available at: www.emeraldinsight.com

3. Greene, E. Walter, Walls, D. Gary and Schrest, J. Larry,1994,'Internal Marketing, The Key to External Marketing Success", Journal of Service Marketing, Vol. 8, No. 4, Available at: www.emeraldinsight.com.

4. Ooncharoen and Ussahawanitchakit, 2009, "Internal Marketing, External Marketing, Organizational Competencies, and Business Performance, International Journal of Business Research, Vol. 10, No. 1, Available at: www.emeraldinsight.com.

5. Farzad, Atousa, Nahavandi, Nasim and Caruana , 2008, The Effect of Internal Marketing on Organization Commitment in Iranian Hotels , American Journal of Applied Sciences, Vol. 5, No. 11, Available at: www.emeraldinsight.com.

6. Roberts-Lombard, Mornay , 2010, “Employees as Customers - An Internal Marketing Study of the Avis Car Rental Group in South Africa“, African Journal of Business Management, Vol. 4, No. 4, Available at http://www.academicjournal.org.

7. Chang, S. Ching and Chang, C. Hae, 2009, " Perceptions of Internal Marketing and Organizational Commitment by Nurses " Journal of Advanced Nursing , Vo. 65, No. 1, Available at: www.emeraldinsight.com.

8. Turkoz, Isil and Akyol, Ayse, 2008, "Internal Marketing and Hotel Performance“, An International Journal of Tourism and Hospitality Research , Vol. 19, No. 1, Available at: www.emeraldinsight.com.

9. Lam, Terry and Zhang, Q. Hanqin, 2003, "Job Satisfaction and Organizational Commitment in the Hong Kong Fast Food Industry“, International Journal of Contemporary Hospitality Management, Vol. 15, No. 4, Available at: www.emeraldinsight.com.

10. Crawford, Alleah and Riscinto-Kozub, Kristen, 2008, "The Role of the Employee: An Exploratory Study in Service Recovery Satisfaction in the Luxury Resort Industry“, Journal of Tourism Insights, Vol. 1, No. 1, Available at: www.emeraldinsight.com.

11. Kazlauskaite, Ruta, Buciuniene, Ilona and Turauskas, Linas, 2006, " Building Employee Commitment in the Hospitality Industry , Baltic Journal of Management , Vol. 1, No. 3 , Available at www.emeraldinsight.com.

12. Fulford, Mark D. 2005, " The Test of a Model of Organizational Justice, Job Satisfaction, and Organizational Commitment Among Hotel Emplotees " Journal of Human Resources in Hospitality and Tourism, Vol. 2, Issue. 1 , Available at: www.emeraldinsight.com.

13. Gounaris, Spiros, 2008, " The Nation of Internal Market Orientation and Employee Job Satisfaction: Some Preliminary Evidence “, Journal of Service Marketing, Vol. 22, No. 1 , Available at: www.emeraldinsight.com. 


\section{أبو رمان وأمدآن]}

14. Ahmed, P.K., Rafiq, M. and Saad, N.M. 2003," Internal Marketing and the Mediating Role of Organizational Competencies", European Journal of Marketing, Vol. 37, No. 9, Available at: www.emeraldinsight.com.

15. Hwang, Ing-San and Chi, Der-Jang, 2005, "Relationship Among Internal Marketing, Employee Job Satisfaction and International Hotel Performance: An Empirical Study", International Journal of Management, Vol. 22, No. 2, Available at: www.emeraldinsight.com.

16. Rydberg, Isabella and Lyttinen, JP, 2005 , Internal Marketing in Hotel Chains: A Case Study of Elite Stadshotell Lulea, PHD Thesis, Lulea University of Technology, Sweden's, Available at: www.emeraldinsight.com.

17. Billy, Bai , Pearl, K. Brewer, Gail, Sammons and Skip, Swerdlow, 2006, "Job Satisfaction, Organizational Commitment and Internal Service Quality: A Case Study of Las Vegas Hotel / Casino Industry , Journal of Human Resources in Hospitality and Tourism, Vol. 5, Issue.2, Available at: www.emeraldinsight.com.

18. Ahmed, P.K. and Rafiq, M. 1995, "The Role of Internal Marketing in the Implementation of Marketing Strategies", Journal of Marketing Practice: Applied Marketing Science, Vol. 1, No. 4, Available at: www.emeraldinsight.com.

19. Rafiq, M. and Ahmed, P.K. 1993, "The Scope of Internal Marketing: Defining the Boundary Between Marketing and Human Resource Management", Journal of Marketing Management, Vol. 9, Available at: www.emeraldinsight.com.

20. Opoku, A. Robert, Atuobi-Yiadom, Nana , Chong, S. Cathryn and Abratt, Russell, 2009, "The Impact of Internal Marketing on the Perception of Service Quality in Retail Banking: A Ghanaian Case" , Journal of Financial Service Marketing, Vol. 13, No. 4, Available at: www.emeraldinsight.com.

21. Snell, Lan and White, Lesley 2009, "An Exploratory Study of the Application of?Internal Marketing in Professional Service Organizations", Service Marketing Quarterly, Vol. 30, Available at: www.emeraldinsight.com.

22. Walker, John, 2009, Introduction to Hospitality, Pearson Prentice Hall, Pearson Education, Inc.

23. www.mota.gov.jo. Ministry of Tourism and Antiquity, Department of Statistics, Amman , Jordan , 2009/2010.

24. Meyer, J. Allen, N. and Smith, C, 1993, "Commitment to Organizational and Occupations: Extension and Test of a Three-Component Conceptualization, Journal of Applied Psychology, Vol. 78, Available at: www.emeraldinsight.com.

25. Allen, N. and Meyer, J., 1990. "The Measurement and Antecedents of Affective , Continuance and Normative Commitment to the Organization, Journal of Occupational Psychology, Vol. 63, Available at: www.emeraldinsight.com.

26. Zeithaml, Valarie, A. Parasuraman, and Leonard Berry. 1985. "Program and Strategy in Service Marketing", Journal of Marketing, Vol. 49, Available at: www.emeraldinsight.com.

27. Kotler, Philip 2006 “ Marketing for Hospitality and Tourism, 5th edition, Prentice Hall Pub.

28. Zeithaml, Valarie, Bitner, Mary and Gremler, Dwayne 2006 "Service Marketing, 5th edition, Prentice Hall Pub.

29. Eisenberger, R., Armeli, S., Rexwinkel, B. , Lynh, P. D., and Rhoades, L. 2001. "Reciprocation of Perceived Organizational Support “, Journal of Applied Psychology, Vol. 86, No. 1, Available at: www.emeraldinsight.com. 